\title{
Examining the link between carbon emission, carbon emission intensity and financial development in Nigeria. A Dynamic ARDL Simulation
}

Kingsley Ikechukwu Okere ( $D$ o.kingsley@gregoryuniversityuturu.edu.ng )

Department of Economics, Gregory University https://orcid.org/0000-0002-1845-4583

Maxwell Onyemachi Ogbulu

Department of Banking and Finance, Abia State University

Obumneke Bob Muoneke

Department of Banking and Finance, Lagos State University

Favour Chidinma Onuoha

Department of Economics, Evangel University

Agbede Moses Oyeyemi

Department of Economics, Adekunle Ajasin University, Akungba Akoko

\section{Research Article}

Keywords: Carbon emission, carbon emission intensity, financial development, dynamic ARDL simulation, STIRPAT, Nigeria

Posted Date: April 15th, 2021

DOl: https://doi.org/10.21203/rs.3.rs-346626/v1

License: (c) (i) This work is licensed under a Creative Commons Attribution 4.0 International License.

Read Full License 
1 Examining the link between carbon emission, carbon emission intensity and financial 
${ }^{1 .}$ Kingsley Ikechukwu. Okere

33 Gregory University, Uturu, Abia State, Nigeria

34 Department of Economics, Banking and Finance

\section{2, Maxwell Onyemachi Ogbulu}

Abia State University, Uturu, Nigeria

Department of Banking and Finance

40 Email: onyemachiogbulu046@gmail.com

\section{$41{ }^{3}$ Obumneke Bob Muoneke}

42 University of Lagos, Akoka-Yaba, Nigeria.

43 Department of Banking and Finance

44 Email: nnannamuoneke70@gmail.com

45 ORCID ID: https://orcid.org/0000-0001-7314-9832

\section{$47 \quad{ }^{4}$ Favour Chidinma Onuoha}

48 Evangel University, Akaeze. Ebonyi State, Nigeria.

49 Department of Economics,

50 Email: fc.onuoha@ evangeluniversity.edu.ng

$51 \quad{ }^{5}$ Agbede Moses Oyeyemi

52 Adekunle Ajasin University Akungba, Akungba Akoko, Ondo State, Nigeria

53 Department of Economics

54 Email: yemi_agbede@yahoo.com

55

56

57

58

59

60

61

62 


\section{Authors' Contributions}

$70 \quad{ }^{1}$ Kingsley Ikechukwu. Okere

71 Conceived and designed the analysis

72 Collected the data

73 Performed analysis

74

$75 \quad{ }^{2,}$ Maxwell Onyemachi Ogbulu

76 Organising and supervising the course of the project or the article and taking the responsibility

77 Wrote the theoretical literature

78 Collected the data

79

$80{ }^{3}$ Obumneke Bob Muoneke

81 Wrote empirical literature

82 Performed analysis

83 Funding: Providing personnel, environmental and financial support and tools and instruments that are

84 vital for the project

85

$86{ }^{4}$ Favour Chidinma Onuoha

87 Collected the data

88 Planning methodology to reach the conclusion

89 Constructing an idea or hypothesis for research and/or manuscript

90

$91 \quad{ }^{5}$ Agbede Moses Oyeyemi

92 Critical Review: Reviewing the article before submission not only for spelling and grammar but also for its

93 intellectual content

94 Taking responsibility in the construction of the whole or body of the manuscript

95 Performed analysis 


\section{Abstract}

102 The need for adequate and consistent policies to mitigate the continuous rise of carbon emission have 103 motivated the energy economist in the past decades to actively involved and explore common economic agents that are driving the rising pattern in the environmental pollution. This study is positioned towards contributing to the on-going debates on this issue by exploring the impact of bank credit to the private sector on aggregate carbon emissions and carbon emission intensity in Nigeria over the period 1971-2016 using dynamic ARDL simulations. Controlling for the influence of fossil energy intensity of consumption and economic globalization, the study found that bank credit to the private sector has a positive significant longrun increasing effect on aggregate $\mathrm{CO} 2$ emission and carbon emission intensity in the economy. Second, the estimated coefficients show that fossil energy intensity of consumption and economic globalization have a significant long-run and short-run increasing impact on aggregate $\mathrm{CO} 2$ emission and carbon

112 emission intensity in the economy. In contrast, the population has a significant long-run and short-run 113 reducing effect on aggregate $\mathrm{CO} 2$ emission and only the long run reducing effect on carbon emission 114 intensity. Third, economic growth has significant short-run and increasing long-run effects on aggregate $115 \mathrm{CO} 2$ emission and a long run increasing effect on carbon emission intensity. In sum, the results show that 116 the economy is yet to transient to renewable energy.

117 Keywords: Carbon emission, carbon emission intensity, financial development, dynamic ARDL 118 simulation, STIRPAT, Nigeria

119 
63

\section{Introduction}

The collaboration of Intergovernmental Panel on Climate Change (IPCC) affirmed carbon emission as the cause of global warming and climate change in the world (IPCC 2018) and warned that if no drastic action is taken to reduce carbon emissions, the physical impact on climate change on the international economy will be significant. The extractions of natural resources in Africa are mostly carried out with the use of heavy machinery that turns out enormous carbon emission (Kwakwa et al., 2018). The broad use of heavy machinery in industrial sector coupled with expansion of existing firms and springing up of new businesses activities are inimical to the environment quality with challenges of spontaneous rise in carbon emission (Letcher 2020 and Lahiani 2020).

According to International Energy Agency (IEA) 2020, Nigeria had estimated 37bn barrels of untapped crude oil reserves at the end of 2019, which contains 15\% of Africa's oil reserves and $16 \%$ of its gas. Appendix 1 reveals the total energy usage in Nigeria, this trend showed Biofuels and waste are major sources of energy in Nigeria, which account for about $80 \%$ of total primary energy consumed in Nigeria (Ben-Iwo, Manovic and Longhurst, 2016). IEA (2020) data showed that greenhouse gas emissions from fossil fuel production used have increased by $16 \%$ since 2015 . Fossil fuel combustion has been the major means of energy generation in the Nigeria economy and have translated into heavy carbon emission. The potential effect of this on climate change is a threat to Nigerian sustainable economic development, by accounting to a projected damage of $6 \%$ to $30 \%$ of gross domestic product by 2050 , this will translate to the loss of US\$ 100 to US\$ 460 billion if drastic measure are not taken to cushion the effect (Amin et al 2020). Record shows that $2.7 \%$ per annum increase in greenhouse gas (GHG) emissions released after three years of landmark Paris Agreement (Le Quéré et al. 2018). The rise in income of households and production activities stimulate economic growth with an intensive demand for heavy technologies and investment in energy intensive sectors (Shoaib et al. 2020; Gill et al. 2019; Liu and Song (2020); Lahiani, 2020). In other words, financial development has the tendency to raise the significant level of carbon emissions either from emerging economies or developing countries (Jiang, Yang and Ma 2019). 


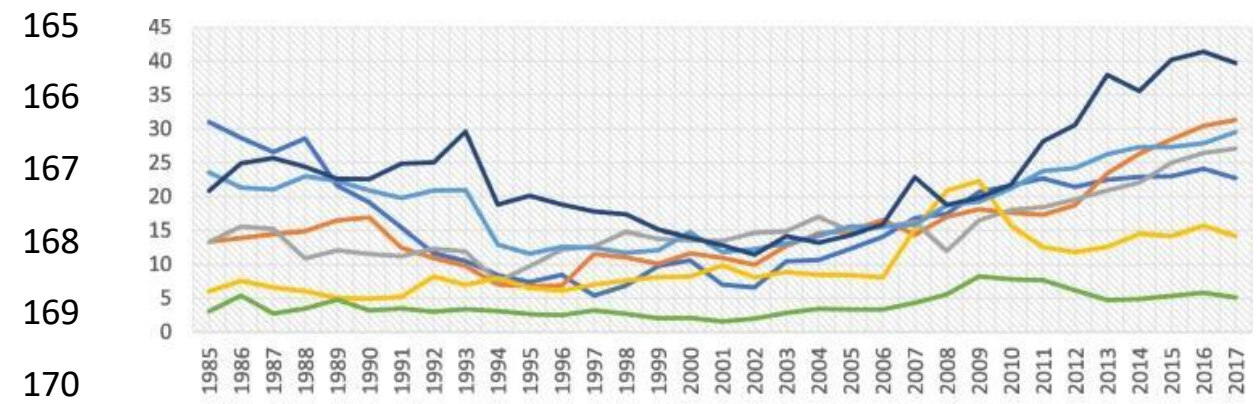

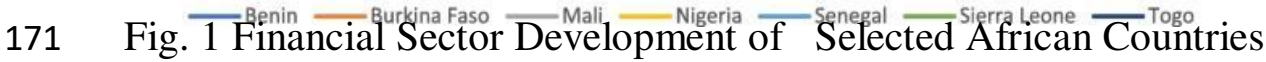

172 Source: WDI (2019)

173 Fig.1 shown the level of financial sector development in selected African countries, it can been 174 seen that, Nigeria has a relative development in the financial sector from year 2006 upward, while 175 domestic credit to the private sector as a percentage of GDP averaged $13.03 \%$ between 2001 and 176 2017. In line with the trend, financial development expands production capacity and social 177 development with a significant pressure mounting on the environment (Aye and Edoja, 2017; 178 Danish and Wang, 2019; WWF, 2018). The rising trend of financial development in Nigeria is 179 associated with the steady growing of carbon emission as shown in Fig. 2, the causes yet to be given adequate attention for policy maker. Deepened financial system with more access to credit by households increases income and expansion of firms' production growth. The disbursement of credit to enhance domestic product supply and creating demand for local and international markets depend on the functioning financial market cause by asymmetric macroeconomic variables (Shahbaz, Shahzad, Ahmad and Alam, 2016). Credit facilities to industrialists pave way for 185 entrepreneurs' to acquire more industrial machines with rise in intensity of carbon emission (Xing, Jiang and Ma, 2017). The promotion of consistent burning of fossils fuels by sectors (oil, gas and coal), untamed carbon dioxide (CO2) releasing into the atmosphere thereby wreaking havoc to environmental quality (Johnsson et al. 2019). Financial development through the financial markets equally enables firms to have access to financial assistance to acquire low carbon emission technologies (Tsaurai, 2019). Financial 192 technology by sectors of the economy as well as reducing greenhouse gas emissions at low pace 193 of economic growth (Hao et al. 2016). In view of this, the initiative of development finance under 194 Central Bank of Nigeria engage in policies formulation and implementation towards new products 195 discovery and creating an enabling atmosphere for financial institutions to deliver services in a 
secure, competitive and sustainable healthy environment in all the sectors of the economy through the Central Bank of Nigeria (Igwebuike, Udeh and Okonkwo, 2019)

The knowledge gap linking carbon emission and carbon emission intensity to financial development in Nigeria motivate the research paper. The depth of financial intermediation in promoting green financing to prevent environmental damage attracted global research interest.

Fig. 2 Carbon Emission: Nigeria Ecological Footprint by Land Type

Data source: Global Footprint Network 2021

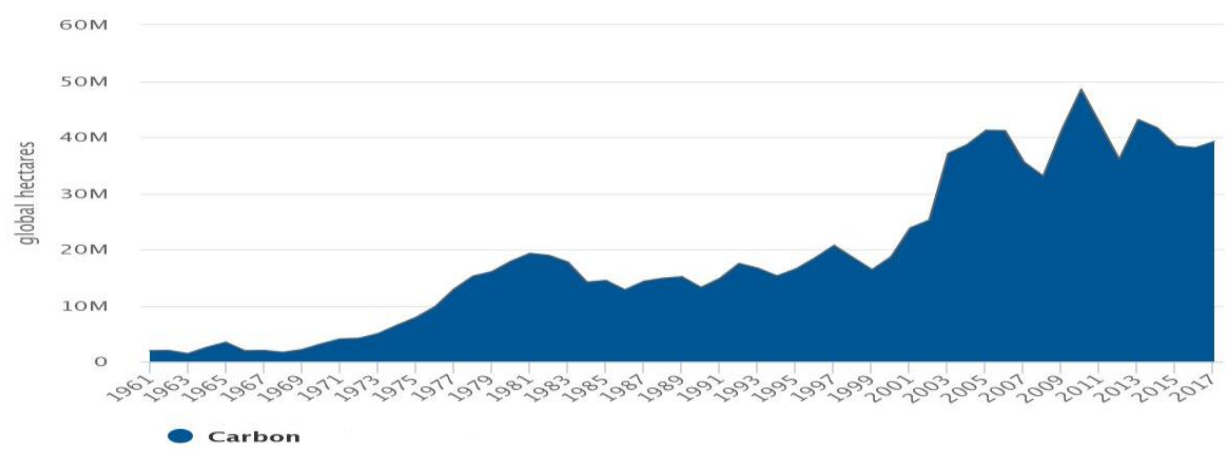

Figure 2: Global Footprint Network 2021

Data source: Global Footprint Network 2021

The financial sector development increase the carbon emission intensity in Nigeria, Fig. 2 shows the rise in carbon emission from year 2001 at its peak. Studies on carbon emission intensity and financial development are still scarce in the existing literature in Nigeria context. The earlier study by ( Aminu et al 2020) adopted Auto-Regressive Distributed Lag technique that failed to capture sufficient (STIRPAT) dynamic features, also, (Omoke et al 2020) used nonlinear autoregressive distributed lag (NARDL) framework to analyze Ecological footprint in Nigeria with no measures of population, affluence and technology for adequate projection policy formulation. Studies such as (Adejumo and Asongu 2020; Adejumo 2020; Ali et al. 2019; Ali et al. 2016; Rafindadi 2016; Riti and Shu 2016) used carbon emissions CO2 to measure degradation in Nigeria. The rise in financial sector development along with the carbon emission increase call for urgent attention for environmental sustainability. The components of carbon and non-carbon emissions degradation in environment formed an all-inclusive measure for sustainable environment (Wang and Dong 2019; Danish and Wang 2019). The country-specific insights findings will facilitates and strengthening policy decision given empirical modelling based on the Stochastic Impact by Regression on Population, Affluence, and Technology (STIRPAT) framework that incorporates carbon emission 
221 intensity variables and proxy of financial development. The use of (ARDL) simulations model for

222 both short and long run estimates will equally give a better interpretation and policy

223 recommendation on implication of carbon emissions intensity and financial market instruments in

224 Nigeria.

225 The remainder of this research paper is organized in sections as follows: A brief earlier literature 226 study is discussed in "Literature review" section. Data and methodology are discussed in "Data 227 and methodology" section. Empirical results and discussion are discussed in "Result and 228 discussion" section and finally, the conclusion in the "Conclusions and policy recommendations" 229 section

230 Theoretical Literature

231 This section is divided into two: theoretical review and empirical review. The empirical review are 232 encapsulated in two form: the discussion area and the tabular form as sown in table 1 below.

233 This subject area is currently submerged with empirical entries from different studies adopting a 234 global perspective, regional perspective and national perspective. The seminal work of Kraft \& 235 Kraft (1978) is credited to be the first empirical entry as they attempted to establish the link 236 between energy consumption, economic growth and carbon emissions, they concluded that 237 economic growth is associated with substantial energy consumption that induces carbon emissions. 238 Recently, attention has been shifted from economic growth to other variables like financial 239 development.

240 The channel through which financial development impacts carbon emissions differs from 241 developing economies to developed economies. In developing economies, in pursuance of 242 economic growth and prosperity, financial system's institutions play a sacrosanct role by extant 243 distribution of funds to investible channels which may not be environmental-friendly ranging from 244 manufacturing firms vis-à-vis its high pollution potential emanating from consistent reliance on 245 traditional energy sources and cheap access to credit to business owners and households enabling 246 them purchase equipment with energy demand. FD in the developing economies' case through the 247 growth channel increases the level of energy consumption especially from traditional sources, 248 which in turn, increases carbon emissions in developing economies (Sardosky, 2010, Sardosky, 249 2011, Chang, 2015, Sethi, et al, 2020; Samreen \& Majeed, 2020). On the other hand, in the case 250 of developed economies, financial development reduces carbon emissions, firstly through the 251 presence of admirable institutional quality, presence of socially responsible and sophisticated 
252 investors and the machinery of bank financial institutions and the stock market collectively 253 engenders investment in green-oriented manufacturing firms with renewable energy-efficient technologies associated with little or no negative environmental effects as opposed to the fossil 255 fuels used in less-developed and developing economies (Samreen \& Majeed, 2020, Tahir, et al 2562020 and Yao \& Tang, 2020). Another school of thought hinged the low C02 emissions in 257 developed economies on the transfer of heavy production plants from developed countries to 258 developing countries where there is a loophole in regulation either tax-based or environment-based 259 by way of foreign direct investment (Shoaib, Rafique, Nadeem \& Huang, 2019).

260

Examining the carbon intensity-financial development nexus, there are two notable channels through which financial development can affect carbon emissions intensity other than economic growth and development channel as recognized in (Hao, et al. 2016, Pan, et al., 2016 and Vujovic, et al., 2018). The second channel will definitely differ from developing economies to developed economies, financial development can assist developing countries in reducing carbon emissions intensity through supporting the adoption of low-carbon energy technologies by way of copymanufacture from developed economies. However, in developed economies, financial development reduces carbon emissions intensity by actively funding research and development activities to decipher numerous low-carbon technologies to support existing technologies (Hao, et al. 2016, Li \& Ouyang, 2019 and Shoaib, et al. 2019). The third channel relies on the discretion of financial institutions and their level of social responsibility reflected in their provision of sophisticated financial assistance and services to green-oriented firms at lower costs (Li \& Ouyang, 2019).

Other stream of literature established positive linkage between environmental degradation indicators and financial development are numerous; such as the work of Shahzad et al, 2017 who employed Autoregressive Distributive Lag model on time series data covering the period of covering 1971-2011 to investigate the association among carbon emission, bank credit and energy use in Pakistan. Their result revealed a direct association between credit to private sector and carbon dioxide emission and between trade openness and $\mathrm{CO} 2$. Further findings indicated a nonlinear association between the variables. In like manner, Zhang and Zhao, 2019 employed GMM in an STIRPAT framework on data ranging from 1996-2015 to examine the linkage between social development and environmental pollution in 30 provinces of China and found that $\mathrm{R} \& \mathrm{D}$ 
282

283

284

285

286

287

288

289

290

291

292

293

294

295

296

297

298

299

300

301

302

303

304

305

306

307

308

309

310

311

312

investment exerted positive influence on $\mathrm{CO} 2$. It was also revealed that a two-way causal-effect existed between financial development index and CO2. Also, analyzing the influence of GDP per capita, energy use, foreign investment, and bank credit to private sectors on environmental quality in Kuwait with data spanning 1980 - 2013, Salahuddin et al, 2018 adopted ARDL bound test and observed that FDI, per capita GDP, financial development and electricity use exerted direct and significant impact on $\mathrm{CO} 2$ emission in the country. A case study of eight Asian nations employed FMOLS technique on data covering the period of 1982 to 2017 to analyze the effect of energy use and domestic credit to private sector on $\mathrm{CO} 2$ emission and found that bank credit, fossil fuel, and urbanization have direct linkage with $\mathrm{CO} 2$ emissions while trade openness reduces $\mathrm{CO} 2$ in the nations under study (Abbasi, et al, 2020). A similar study was carried out by Tahir et al, 2020 in South Asian countries with same econometric approach on longitudinal data covering the period of 1990 - 2014 and the result showed that domestic credit (as financial development indicator), energy use, and GDP have positive impact on carbon emission. It was also revealed that globalization reduces $\mathrm{CO} 2$ in the region.

The effect of energy mix and financial development on environmental degradation was explored by Ali et al (2019) in Nigeria. Utilizing ARDL approach on time series data spanning 1971 to 2010, they found that at both long and short run periods, credit to private sector exerted direct and significant influence on CO2 emission. It was equally found that GDP and energy use have direct linkage with $\mathrm{CO} 2$ in the long run but exhibit inverse association with $\mathrm{CO} 2$ in the short period. Yasin et al. (2020) exploring the association among domestic credit to private sector, political institution, energy use and environmental degradation in a pool of 59 less developed nations with data covering 1996 to 2016, adopted GMM and EGLS techniques and found that CPS, urbanization and electricity use have direct influence on CO2 in lower-income nations. The study further validates the EKC hypothesis. A similar study was also conducted by Yasin, Ahmad, and Chaudhary, 2020, who proxied environmental quality with ecological foot print and grouping 110 nations into high-income and low-income countries, using same GMM model on data spanning 1996 to 2016, they found that financial development and energy use increase ecological foot print in high-income nations while urban population, trade openness and political institution have inverse influence on ecological footprint. Pooling 17 emerging nations to explore the effect of disaggregated bank development indices on ecological foot print with data ranging from 1991 2013, Destek, 2019, adopted panel regression approach and the findings showed that bank credit 
and stock returns mitigates pollution while no significant linkage was seen between banking development, bond market development and ecological foot print. Utilizing non-linear ARDL technique on data spanning 1971 to 2014 in Nigeria, Omoke et al, 2020 found that rise in financial development exert inverse influences on ecological footprint but a decrease in financial development escalates ecological foot print in Nigeria. It was also revealed that GDP, energy use, urban populace, and globalization positively contribute to ecological foot print in Nigeria.

Second strand of literature confirms that the relationship between banking credit and carbon dioxide emission is indirect in nature. Example is the work of Zaidi et al, 2019 who examined the connectivity among globalization, domestic credit to private sector and carbon emissions for the APEC nations and employing Westerlund cointegration technique on data spanning 1990 - 2016 found an inverse association between domestic credit and $\mathrm{CO} 2$. Further findings indicated that globalization reduces $\mathrm{CO} 2$ while confirming the presence of EKC hypothesis in APEC nations. A study in Pakistan on the linkages among domestic credit, energy use, economic growth and carbon emission utilized simulated ARDL on data covering the period of 1982-2018 and found that while financial development, foreign direct investment, real GDP and energy use raise level of CO2 emission, domestic credit reduces it (Khan, Teng, and Khan, 2020). Employing same technique in Chinese 30-provinces on data spanning 1997 - 2016, Guo and $\mathrm{Hu}, 2020$ established an inverse association between stock returns and $\mathrm{CO} 2$ emission. The indirect influence of financial development on of environmental degradation indicator entails that China is successful in giving out its credits or financial facilities to sponsor environmental friendly projects. Thus, such projects will lead to trading on cost-efficient energy technology such as investment in business vehicles and real estate term loans which is more of low-carbon finance Nwani and Omoke (2020) employed STIRPAT on the ARDL framework to examine the association between bank credit and low-carbon emission in Brazil with data spanning 1971 to 2014. The findings of their study revealed that credit to private sector promotes low-carbon emission since inverse linkage existed between them. Utilizing the same econometric technique on data spanning 1992 - 2014, Tian et al, 2017 analyzed the impact of domestic credit to private sector on CO2 intensity in China and their result showed the existence of cointegrating relationship between the variables. Also, they found that both innovation and domestic credit have inverse influence on carbon intensity while poor correlation existed between stock returns and carbon emission/GDP intensity. 
The third strand of literature found mixed results on the association between carbon dioxide emission and financial developments. To start with, Ibrahim, 2018 explored the linkage between foreign trade, domestic credit and $\mathrm{CO} 2$ emission intensity in middle-income nations with data ranging from 1991-2010. Employing the EKC framework, their findings showed that financial development reduces carbon emission intensity in upper middle-income nations and Europe while exacerbates pollution in Europe. A case study of Chinese provinces on the linkage between bank credit and carbon dioxide utilized panel cointegrating techniques (FMOLS, DOLS and PVECM) on data covering the period of 2001-2015 and observed that financial development exerted direct influence on $\mathrm{CO} 2$ in some provinces and inverse impact on $\mathrm{CO} 2$ in other provinces (Zhao and Yang, 2020). Considering the effect bank credit to private sector on environmental quality in $G$ and N-countries, Zafar et al, 2019, employed cointegration method and established that financial development indictor reduces $\mathrm{CO} 2$ in G-7 nations while it raises $\mathrm{CO} 2$ in $\mathrm{N}-11$ nations. The study validates the EKC hypothesis. The findings also showed a two-way causality existing between fd index and carbon dioxide emission. A study in Chinese provinces and national economy, employed spatial panel models on data ranging from 2007 to 2016 and found that financial development at provincial level and population raises carbon intensity while at national level, the linkage was inverse (Liu and Song, 2020). Shahbaz et al, 2020 employed an EKC on ARDL framework to explore the environmental effect of economic growth, financial development and research and development expenses for the UK with data spanning 1970 - 2017. Their findings validated the EKC hypothesis.

The fourth strand of literature proved that there was no linkage between domestic credit to private sector and environmental degradation based on the level of significance. For instance; Lu, 2018 analyzed the influence of electricity use and bank credit on carbon emissions in 12 Asian developing nations with longitudinal data data spanning 1993-2013. Adopting panel cointegration technique, the study found that the bank credit had no significant effect environmental quality while GDP and energy use exerted direct influence on CO2 emission. In same manner, Chen et al, 2019 adopted DSUR method on data spanning 1980 to 2016 in the examination of the influence of domestic credit, energy sources on carbon dioxide emission in Central Eastern European nations and found no significant linkage between credit to private sector and carbon dioxide emission. However, they established that globalization and both energy sources increased CO2. 
373 Another strand of literature reinforces that activities of construction firms, manufacturing firms 374 and raw materials suppliers for construction can contribute to an increase in carbon emissions other 375 than financial development as widely discussed in academic literature. C02 emissions generate 376 more impact on the environment and one of the main polluting industries is that of cement and its 377 components. Asides financial development, population, urbanization and industrialization also 378 contributes to increase in carbon emissions in developing economies already substantiated with 379 vast empirical evidences (Nag \& Parikh, 2000). But more differently, construction and 380 manufacturing activities also contributes greatly to environmental degradation apart from financial development if mismanaged and by-products are not immersed as a raw material in creating other common construction materials (Carvalho, et al, 2014; Mendes, et al 2019 and Azevedo, et al 2019). Elaborating further on the environmental impacts of cement production and other building components; Azevedo, et al (2019) confirmed that application of locally manufactured ceramic materials for civil construction contributes to environmental degradation as wastes are discarded directly into host environment. In similar vein, the processing of ornamental stones in Brazil increases environmental pollution as each operational stage of ornamental stone processing generates a considerable amount of sludge wastes which if not channeled into re-production of another finished good will constitute environmental nuisance (Carvalho, et al 2014). A more 390 practical example of recycling wastes into more acceptable and environmental-friendly finished goods is seen in the experiment carried out by Carvalho, et al (2014); where sludge waste generated

392 from the cutting process of granite and limestone were dried and crushed in a media alongside a 393 type CPII 32 cement to produce soil-cement blocks. The heavy reliance on traditional fossil fuels for production and the poor handling of raw material sources (disposing and extracting) sums up 395 the negative effects of cement production and its various alternatives on its host environment 396 (Amaral, et al 2019). Further fears of environmental pollution is heightened in the case of 397 increasing iron-ore production owing to mass storage of by-products (tailings) in dams which most 398 times ruptures and amount to leakages to its host environment, a feasible solution still resides in 399 reusing the wastes to produce materials for constructive purposes to reduce environmental damage 400 (Zhao, et al, 2014 and Mendes, et al 2019).

401 Table 1 shows the summary of empirical reviews and related findings. 
Table 1: Summary of selected empirical literature

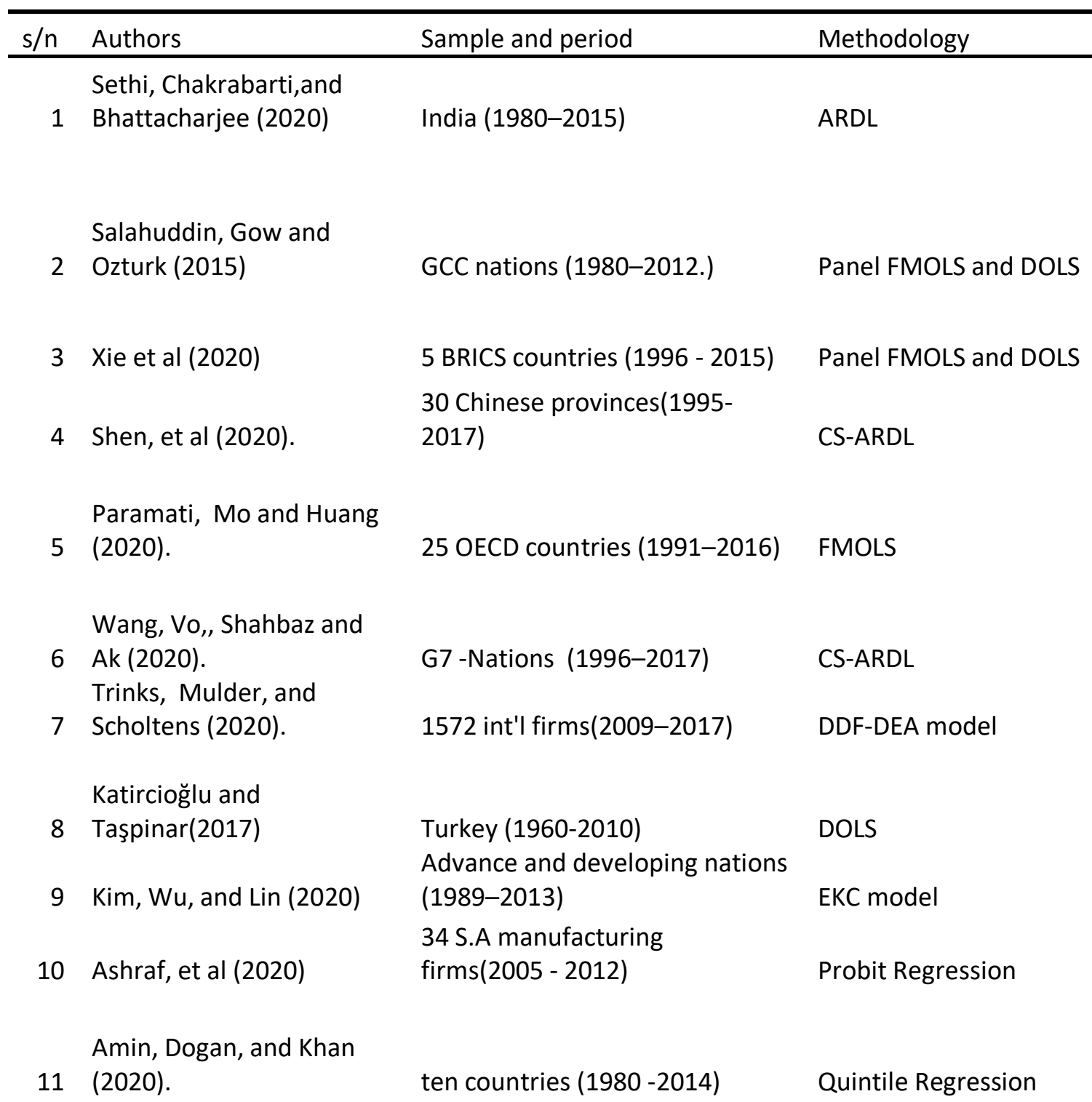

Globalization, per capita GDP and energy use
stimulates $\mathrm{CO} 2$ emission

GDP and electricity intensity exert positive significant influence on environmental degradation indicator in the long-period while there exist no significant shortrun relationship among them.

Public debt securities make reduces carbon emission while private credit hinders increases $\mathrm{co} 2$

Natural resources rent and financial development have a positive influence carbon dioxide

per capita income and financial deepening exert a direct impact on environmental quality while FDI and openness reduce $\mathrm{CO} 2$

FD and natural resources have direct association with $\mathrm{CO} 2$ while Agriculture value added has inverse relationship with carbon emission

Financial development index influences $\mathrm{CO} 2$ inversely. Financial development has inverse linkage with carbon emission. Also, there is evidence of EKC hypothesis in Turkey.

Validates the existence of Kuznet hypothesis

Financial slack has a direct effect on carbon performance.

Existence of inverted U-shape relationship. Also financial development indicators reduces carbon emission. 
Charfeddine and Kahia

12 (2019).

Kayani, Ashfaq and

13 Siddiqu (2020).

14 Khan, Peng and Li. (2019). 193 Nations (1990-2017)

Saud, Chen and Haseeb

15 (2020).

16

Huang and Zhao (2018).

17 Lin and Agyeman (2020).

Brouwers, Schoubben,

18 and Hulle (2018).

Khan, Ju, Latif and Khan

19 (2020).

Gokmenoglu,Taspinar and

20 Rahman (2020).

-2015)

2014)

European Union Emission

Trading Scheme

(2005-2012)

Pakistan (1990 - 2015)

Turkey (1960-2010)
24 Nations-MENA Region (1980

PVAR

10 emitter nations(1990-2016)

PFMOLS and VECM

SUR, 3-Stage LS and system GMM

OBOR-initiative nations(1990-

FMOLS

30 provinces in China (2000-

47 SSA nations (1980 - 2014)

ARDL

extended STIRPAT and GMM

ARDL

fixed effect instrumental

variables
Renewable energy and financial development have negative and significant effect on $\mathrm{CO} 2$

Financial development and urbanization exert positive significant influence on $\mathrm{CO}$. renewable energy has inverse impact on Carbon dioxide while no significant association between Globalization and $\mathrm{Co} 2$

Financial development reduces $\mathrm{CO} 2$ while energy consumption and economic growth increase $\mathrm{Co} 2$

Financial development, energy consumption, economic growth, and trade positively affects ecological footprint, while globalization reduces ecological footprint.

A U-shaped association between EXC and the per capita income. various financial indicators reduced $\mathrm{CO} 2$ emissions embodied in exports

Fossil fuel energy intensity and other energy sources have inverse influence on carbon emission

Financial development exhibit direct effect on environmental quality.

Access to Electricity, Financial development, and population growth have a positive relationship with $\mathrm{CO} 2$ emission. Natural resources shows insignificant relationship with $\mathrm{CO} 2$ emission

Financial development exert negative impact on both $\mathrm{CO} 2$ and ecological footprint. Military expenditure and economic growth have positive influence on environmental degradation indicators. 
21 Dar and Asif (2017).

Asumadu-Sarkodie and

22 Owusu (2016).

Ahmad, Khan, Rahman

23 and Khan (2018).

Gokmenoglu and

Sadeghieh (2019).

403

404
India (1971-2013)

Sri Lanka (1971 to 2012)

ARDL

China (1980-2014)

Turkey ECM
ARDL reveal that there is no long run equilibrium association among the variables. Energy use has a positive impact on carbon emissions. EKC was no established. Financial development and energy consumption increased $\mathrm{CO} 2$.

Financial development and industrialization exert positive influence on $\mathrm{CO} 2$ while GDP and population have negative effect on $\mathrm{CO} 2$

Energy use, economic growth and financial development have positive and significant impact on environmental degradation.

Johansen co-integration test and Economic growth and credit to private sector reduces 


\section{Model and methodology}

406

407

The IPAT model was suggested by Ehrlich and Holdren (1971) as a paradigm, whereby economic activities affect greenhouse emissions and thus lead to environmental pollution. A basic environmental effect equation is therefore in the form:

$I=P A T$

I mean environmental effects, $\mathrm{P}$ means population, $\mathrm{A}$ means affluence, and $\mathrm{T}$ represents technology. Therefore, the IPAT model describes the impact of human activities on the environment as a function of income/affluence, population, and technology (York et al. 2003). Therefore, the IPAT model explains the environmental effect of human activities on the environment as a function of income, population, and technology (York et al. 2003).In line with IPAT projections, Dietz and Rosa (1994) have suggested the stochastic impact on population, affluence, and technology (STIRPAT) by regression to help the statistical test conditions. The model STIRPAT is represented as:

$I=a P^{b} A^{c} T^{d} \varepsilon$

The above model identifies a,b,c and as scales exponents of P,A, and T respectively. $\varepsilon$ is the white noise and the is shown in log-form below using the standard STIRPAT model is given as:

$\ln I=\ln a+b(\ln P)+c(\ln A)+d(\ln T)+\varepsilon$

In the aforementioned, $\mathrm{b}, \mathrm{c}$ and $\mathrm{d}$ describe the predicted environmental impact innovation in the selected explanatory variable by 1 percent change, if the remaining other determinant factors remain unchanged. Using technology $(\mathrm{T})$ in Equation 3, other variables' effect could be captured in STIRPAT model (see, Dietz and Rosa 1994). Several new studies have expanded the STIRPAT model to explore other factors' effect (Huang and Zhao, 2018; Zhang and Zhao, 2019; Nwani and Omoke, 2020). The STIRPAT model is expanded to include the effects on the private sector of domestic credit by banks in line with the intent of this study. The STIRPAT extended model takes shape:

$\ln I=\alpha_{0}+\alpha_{1}(\ln P)+\alpha_{2}(\ln A)+\alpha_{3}(\ln$ Fossil $)+\alpha_{3}(\ln P \operatorname{crsg})+\alpha_{3}(\ln E \operatorname{cg} e)+\varepsilon$

Where,

$\ln I$ represents the environmental impact of carbon dioxide emissions. This study employs two variables such as: aggregate carbon dioxide emissions (CO2) and carbon emission per unit of gross 
domestic product (lnCEI) to extend the understanding of the level environmental challenges from the activities of the financial system. These variables can either be measured as metric tons per capita denoted by CO2 (see, Zhang and Zhao, 2019; Shahzad et al, 2017; Abbasi, et al, 2020; and Ali et al, 2019, etc.), or as carbon emission per unit of gross domestic product denoted by Carbon emission intensity (CEI) (see Nwani and Omoke, 2020; Ibrahim, 2018; Liu and Song, 2020 etc). $\ln P$ is the population, $(\ln A)$ is economic growth, $\ln$ Fossil is fossil energy consumption GDP per capita, $\ln$ Pcrsg is the financial development, $\ln E c g e$ is the globalization index, $\varepsilon$ is the stochastic error term. All the variables are sources from World Bank Indicators from the period of 1972 to 2016.

Financial development is one of the major explanatory variable measured by the domestic credit to private sector as a percentage of GDP. Bank credits to business firms can lead to increase in production and technological progress via purchase of heavy machines which in turn emits carbon into the environment causing degradation of the atmosphere or credits to private sector will enable business expansion which will lead to economic growth and then to air pollution from machines (see, and it has been incorporated in the works of Omoke et al, 2020; Yasin, Ahmad, and Chaudhary, 2020; Destek, 2019; Zaidi et al, 2019, etc. However, it has been posited credit to private sector influences carbon emissions by business effect, consumer and technological influence.

Gross domestic product is used to proxy Affluence. It represents the economic growth calculated as real GDP per capita that is, at constant 2000 US dollars. Rising economic growth due to economic activities lead to high energy demand and demand for energy consuming goods which in turn leads to environmental pollution as a result of carbon emission and this has been adopted in various literatures (see Salahuddin et al, 2018; Saud, Chen and Haseeb, 2020; Gokmenoglu and Sadeghieh, 2019; Tahir et al, 2020). Economic growth brings about increase in energy consumption which leads to carbon dioxide emissions (AhAtil et al, 2019).

Population is measured as the total number of people living in and area over a specified time period. It is one of our major independent variables. Theoretically, there has been two perspective of literature on the linkage between population and carbon dioxide emission such as; i). Ecological theory of modernization which posit positive relationship between modernization or population and $\mathrm{CO} 2$ emission and II). The urbanization transition theory which predicts that population has 
464

465

466

467

468

469

470

471

472

473

474

475

476

477

478

479

480

481

482

483

484

485

486

487

488

489 neutral effect on CO2 emission (Khan et al, 2020). This has been adopted by Asumadu-Sarkodie and Owusu. 2016; Khan, Ju, Latif and Khan, 2020, etc).

Controlling for the influence of fossil energy intensity and globalization index for robust analysis. We used fossil energy consumption intensity calculated as aggregates of oil, coal, and natural gas consumptions in million tonnes of oil equivalent per real GDP. Recent studies have also adopted it (such as, Liu and Song, 2020; Shahzad et al, 2017; Lin and Agyeman, 2020; Guo and Hu, 2020 etc.). Globalization through free trade and capital increases production and boosts economic growth which in turn hamper the environmental quality via carbon dioxide emission due to increase in energy demand and consumption. So directly or indirectly, it contributes to environmental hazards by scale effect, composition and technological influence. (Shahbaz et al. 2016) and it has been incorporated in empirical studies (see Abbasi, et al, 2020; Saud, Chen and Haseeb, 2020; Kayani, Ashfaq and Siddiqu, 2020, etc.). It is also one of the control variables for this study. The detail explanations are highlighted in table 2 .

\section{The ARDL-bounds cointegration test}

The long run association among the variables in equation 4 is investigated using the autoregressive distributed lag model (ARDL) known as bound testing. The technique is the most favored approach of literature co-integration considering its econometrics advantages such as; it offers robust and reliable estimates in both small and large samples, ii) it is the most acceptable technique as long as none of the variables is integration of order I(2). (iii) It offers tools for the derivation of short and long-term model estimates when cointégration among variables is verified (Pesaran et al. 2001). The empirical formula of the ARDL model is based on the log-linear specification in Equation 4 and it is provided in Equations (5) and (6) for carbon dioxide (CO2) and carbon intensity (CEI) aggregates, respectively

$$
\begin{aligned}
& \Delta \operatorname{lnCO} 2_{t}=a_{0}+\sum_{i=1}^{p} a_{1 i} \Delta \operatorname{lnCO} 2_{t-1}+\sum_{i=1}^{p} a_{2 i} \Delta \ln P_{2 t-1}+\sum_{i=1}^{p} a_{3 i} \Delta \ln A_{3 t-1}+\sum_{i=1}^{p} a_{4 i} \Delta \ln F o s s i l_{4 t-1} \\
& +\sum_{i=1}^{p} a_{5 i} \Delta \ln P \operatorname{csrg} g_{5 t-1}+\sum_{i=1}^{p} a_{6 i} \Delta \ln E c g e_{6 t-1}+a_{7} \operatorname{lnCO} 2_{t-1}+a_{8} \ln P_{t-1}+a_{9} \ln A_{t-1} \\
& +a_{10} \operatorname{lnFossil}_{t-1}+a_{11} \operatorname{lnP}_{\text {Psrg }} \text { f }-1_{1}+a_{12} \operatorname{lnEcge}_{t-1}+a_{D} \operatorname{lnTBr}_{t-1}+\varepsilon_{t}
\end{aligned}
$$


$\Delta l n C E I_{t}=b_{0}+\sum_{i=1}^{p} b_{1 i} \Delta \operatorname{lnCEI_{t-1}}+\sum_{i=1}^{p} b_{2 i} \Delta \ln P_{2 t-1}+\sum_{i=1}^{p} b_{3 i} \Delta \ln A_{3 t-1}+\sum_{i=1}^{p} b_{4 i} \Delta \ln F o s s i l_{4 t-1}$

$$
\begin{aligned}
& +\sum_{i=1}^{p} b_{5 i} \operatorname{LnPCsrg}_{5 t-1}+\sum_{i=1}^{p} b_{6 i} \Delta \operatorname{lnE} \operatorname{lnge}_{6 t-1}+b_{7} \operatorname{lnCO} 2_{t-1}+b_{8} \ln P_{t-1}+b_{9} \ln A_{t-1} \\
& +b_{10} \operatorname{lnFossil}_{t-1}+b_{11} \operatorname{lnPcsrg}_{t-1}+b_{12} \operatorname{lnEcge} e_{t-1}+b_{D} \operatorname{lnTBr}_{t-1}+\varepsilon_{t}
\end{aligned}
$$

493

494

495

496

497

498

499

500

501

502

503

504

505

506

$$
\begin{aligned}
\Delta \operatorname{lnCEI}_{t}=a_{0} & +\sum_{i=1}^{p} a_{1 i} \Delta \ln C E I_{t-1}+\sum_{i=1}^{p} a_{2 i} \Delta \ln P_{2 t-1}+\sum_{i=1}^{p} a_{3 i} \Delta \ln A_{3 t-1}+\sum_{i=1}^{p} a_{4 i} \Delta \operatorname{lnFossil}{ }_{4 t-1} \\
& +\sum_{i=1}^{p} a_{5 i} \Delta \ln P \operatorname{csrg} \operatorname{sit}_{5 t-1}+\sum_{i=1}^{p} a_{6 i} \Delta \ln E \operatorname{cge} e_{6 t-1}+\lambda_{1} \text { ecm }_{t-1}+\varepsilon_{t}
\end{aligned}
$$


The dynamic simulations of using ARDL framework

\section{Dynamic ARDL Simulations}

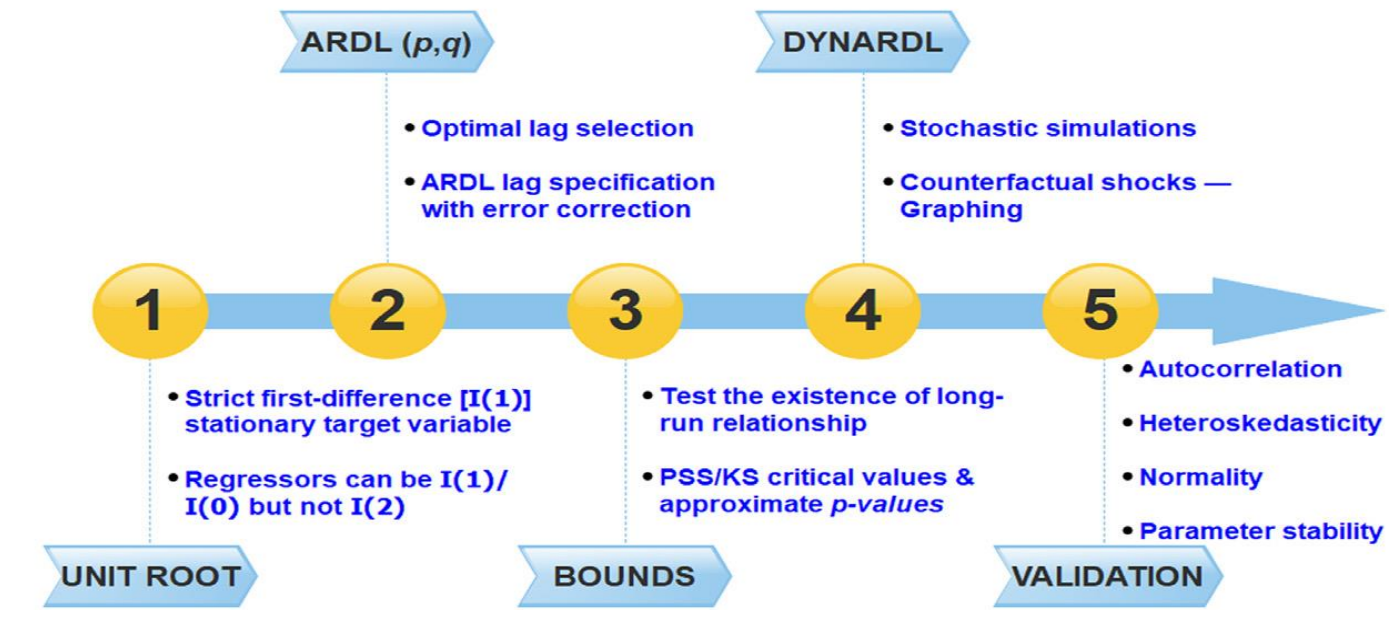

Figure 3: Econometric steps in the application of Dynamic ARDL Simulation

\section{Sources: Sarkodie and Owusu (2020)}

The novel dynamic ARDL Simulation was introduced by (Jordan and Philips 2018) and credited for solving the traditional ARDL model's problems in examining the long-run and short-run model specifications. According to Sarkodie and Owusu (2020), the dynamic simulated ARDL model can stimulate, estimate, and automatically plots to predict graphs of negative and positive changes in the variables and their short and long-run relationships robotically. The application of this model follows some econometric protocol, as shown in (figure 3). First, the ARDL bounds testing procedure used in the novel dynamic ARDL simulations requires a strict first-difference stationary, I (1) dependent variable (Jordan and Philips 2018). This implies that the dependent variable must be non-stationary at the level $I(0)$ to apply cointegration. Second, bounds testing procedure with a dependent variable violating the initial conditions can be tested using the standard but modified ARDL bounds test with surface regression (Kripfganz and Schneider 2019). Several unit root tests can be employed to test this conditional requirement, such as augmented DickeyFuller (ADF), Phillips-Perron (PP), among others. Third, all sampled independent variables can either be $I(0)$ or integrated of order one, $I(1)$ but not greater than $I(1)$ devoid of a structural break, autocorrelation, and heteroskedasticity. They are represented as thus: 


$$
\begin{aligned}
\Delta \operatorname{lnCO} 2_{t}=a_{0} & +\psi_{0} \operatorname{lnCO2}_{t-1}+\varphi_{1} \Delta \ln P_{t}+\psi_{1} \ln P_{t-1}+\varphi_{2} \Delta \ln A_{t}+\psi_{2} \ln A_{t-1}+\varphi_{3} \Delta \operatorname{lnFossil}{ }_{t} \\
& +\psi_{3} \operatorname{lnFossil}_{t-1}+\varphi_{4} \Delta \operatorname{lnPcsrg}_{t}+\psi_{4} \operatorname{lnFossil}_{t-1}+\varphi_{5} \Delta \operatorname{lnEcge} t+\psi_{5} \operatorname{lnEcge}_{t-1} \\
& +\varepsilon_{t}
\end{aligned}
$$

$$
\begin{aligned}
\Delta \operatorname{lnCEI}_{t}=b_{0}+ & \pi_{0} \operatorname{lnCEI}_{t-1}+\theta_{1} \Delta \ln P_{t}+\pi_{1} \ln P_{t-1}+\theta_{2} \Delta \ln A_{t}+\pi_{2} \ln A_{t-1}+\theta_{3} \Delta \operatorname{lnFossil}{ }_{t} \\
& +\pi_{3} \operatorname{lnFossil}_{t-1}+\theta_{4} \Delta \operatorname{lnPcsrg} t+\pi_{4} \operatorname{lnFossil}_{t-1}+\theta_{5} \Delta \operatorname{lnEcge} e_{t}+\pi_{5} \operatorname{lnEcge}_{t-1} \\
& +\varepsilon_{t}
\end{aligned}
$$

Using the dynamic ARDL error correction term algorithm for Equation (9) and (10), 5,000 simulations are performed from a multivariate normal distribution. Two specific criteria must be met before implementation to ensure accurate and reliable simulation estimates. Based on these criteria, it considers the following preliminary steps. First, unit-root analysis measures the order integration among the variables to ensure that none of the variables has a unit root. Second, a Pesaran et al. (2001)-based ARDL-bound test is implemented to determine whether cointegration among variables exists. Confirmation of co-integration is a requirement for the implementation of dynamic simulations of the mentioned ARDL models. 
561 Table 2: Definition and description of variables

\begin{tabular}{llllllllll}
\hline Definitions & Variables & Mean & Median & Max & Min & Std. Dev. & Skew & Kurt & sources \\
\hline CO2 emissions (kg per 2010 US\$ of GDP) & CEI & 0.37945 & 0.35285 & 0.6455 & 0.22613 & 0.11649 & 0.63195 & 2.4380 & WBDI \\
CO2 emissions (kt) & CO2 & 71474.3 & 67056.6 & 131685. & 32280.6 & 29819.6 & 0.51647 & 2.0409 & WBDI \\
Population, total & $\mathrm{P}$ & $1.10 \mathrm{E}+0$ & $1.04 \mathrm{E}+0$ & $1.86 \mathrm{E}+0$ & $5.73 \mathrm{E}+0$ & $3.77 \mathrm{E}+0$ & $4.03 \mathrm{E}-01$ & $2.01 \mathrm{E}+0$ & WBDI \\
GDP per capita (constant 2010 US\$) & $\mathrm{A}$ & 1786.88 & 1766.48 & 2563.9 & 1324.29 & 395.246 & 0.41122 & 1.8940 & WBDI \\
Fossil energy consumption in Mtoe to GDP constant 2010 US\$ & Fossil & 17.9801 & 18.9523 & 22.8447 & 5.96777 & 4.01972 & -1.61442 & 4.9441 & WBDI \\
Index of economic globalization de jure (KOFEcGIdj) & Ecge & 46.5492 & 45.7333 & 55.6326 & 37.5074 & 4.81495 & -0.06171 & 2.2393 & KOF \\
\hline
\end{tabular}

$562 \mathrm{WBDI}=$ the World Bank Development Indicators, (Available online: https://databank.worldbank. org/home.aspx); KOF globalization index

563 computed by Gygli et al. (2019) Available online: https://kof.ethz.ch/en/forecasts-andindicators/indicators/kof-globalisation-index.html

564

565 

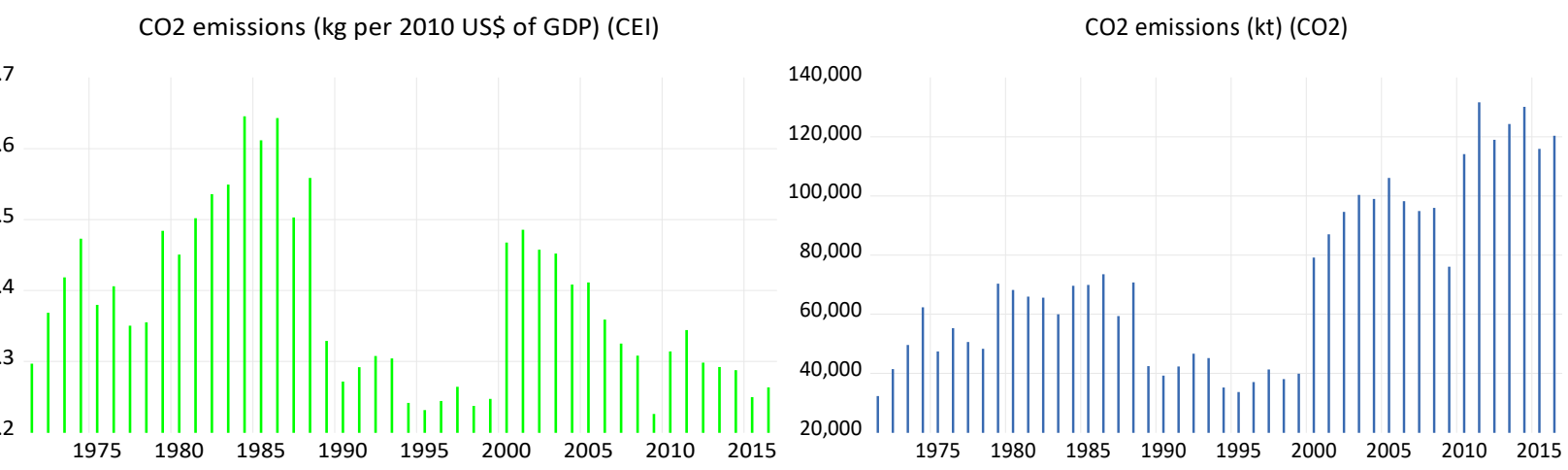

567

Population, total $(\mathrm{P})$

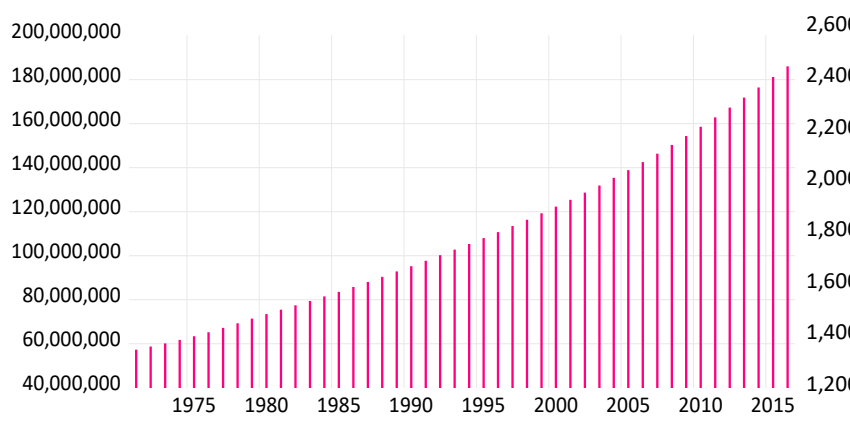

GDP per capita (constant 2010 US\$) (A)

600

400

200

2,000

1,800

1,600

1,400

\section{0}

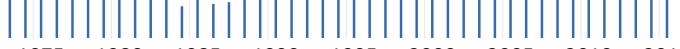

569
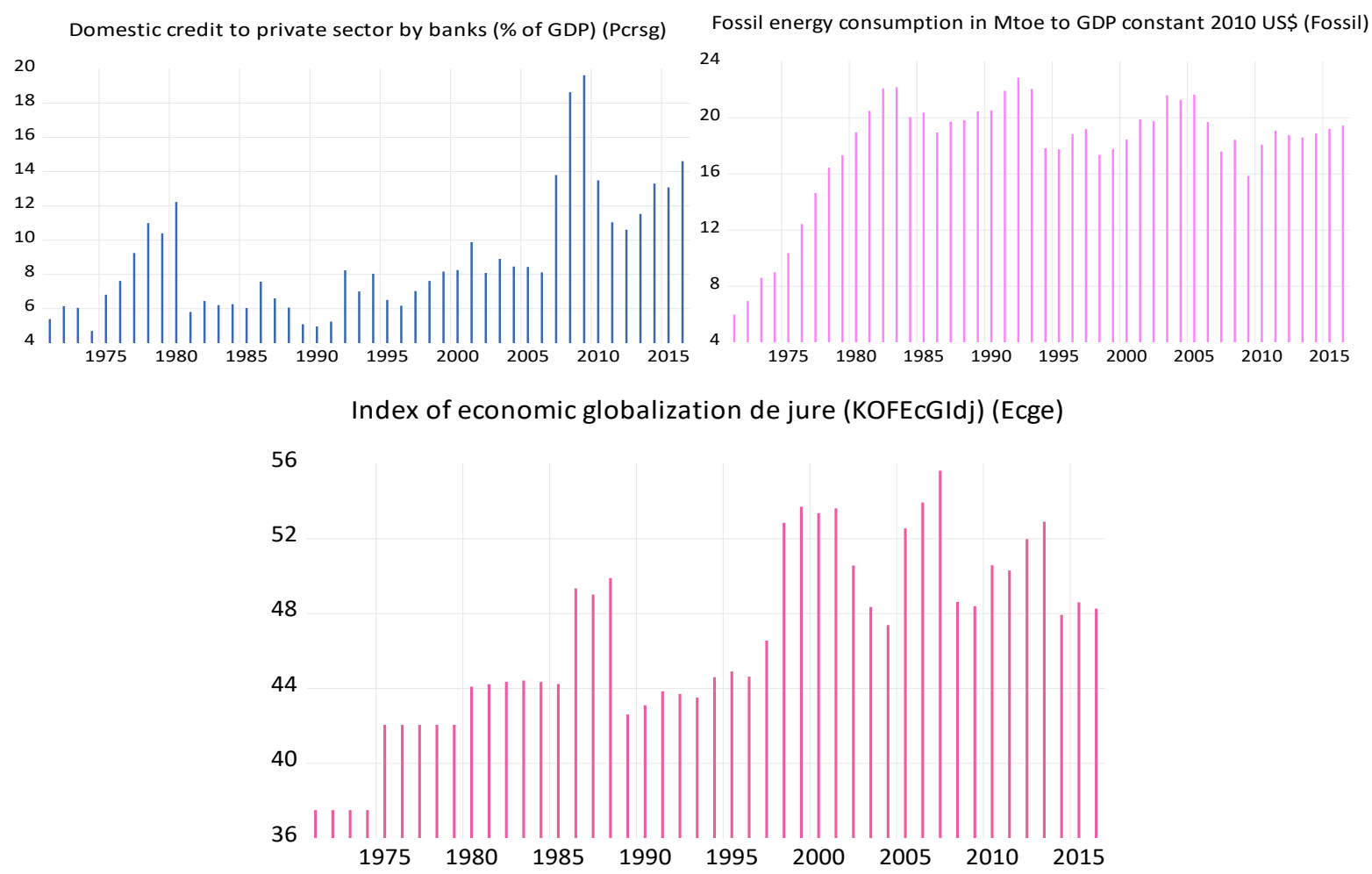

572 Figure 4: Line plot of the variables from 1971 to 2016. Sources see in Table 2 above 
Plot A

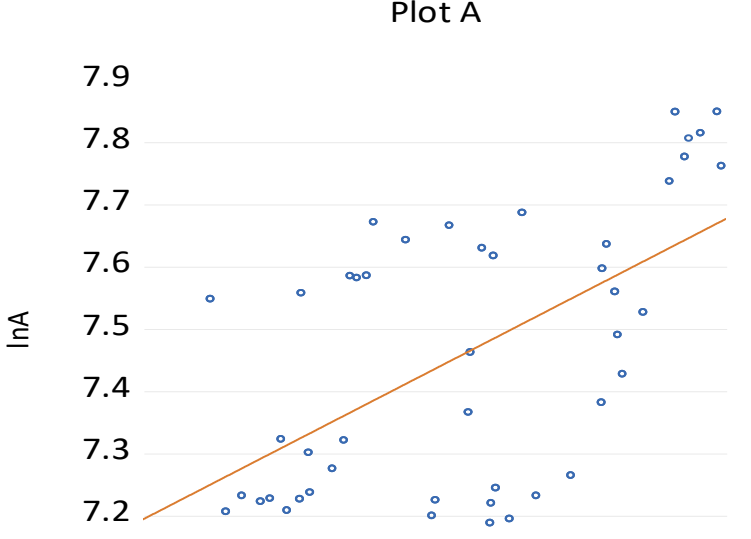

7.1 $\begin{array}{lllll}10.2 & 10.6 & 11.0 & 11.4 & 11.8\end{array}$

573

574

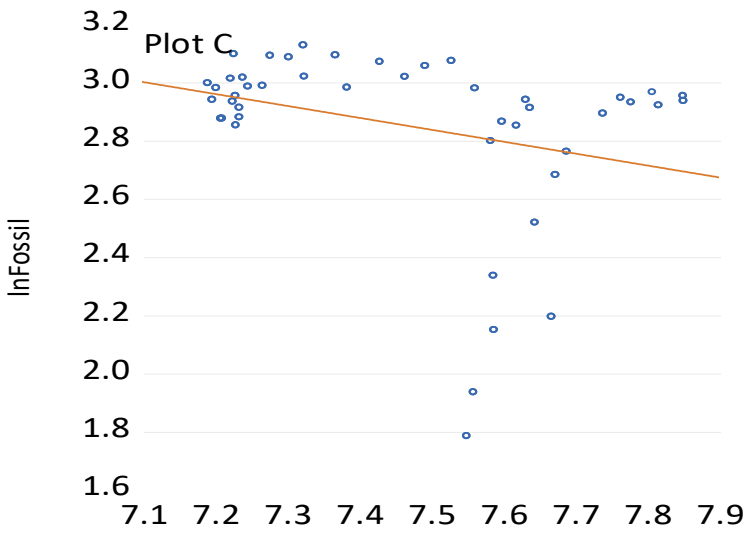

575

576

\section{Preliminary investigation}

578 Figure 4 shows the time evolution of the selected the variables from 1971 to 2016, while figure 5 579

580

581

582

583

584

585

586

587

588

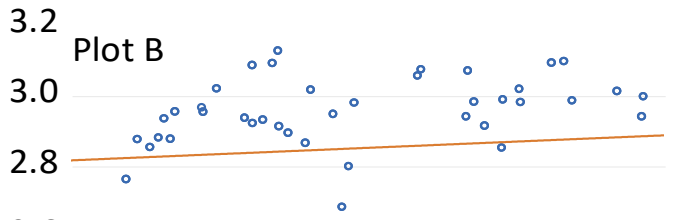

2.6

2.4

2.2

2.0

1.8

1.6
Inco2

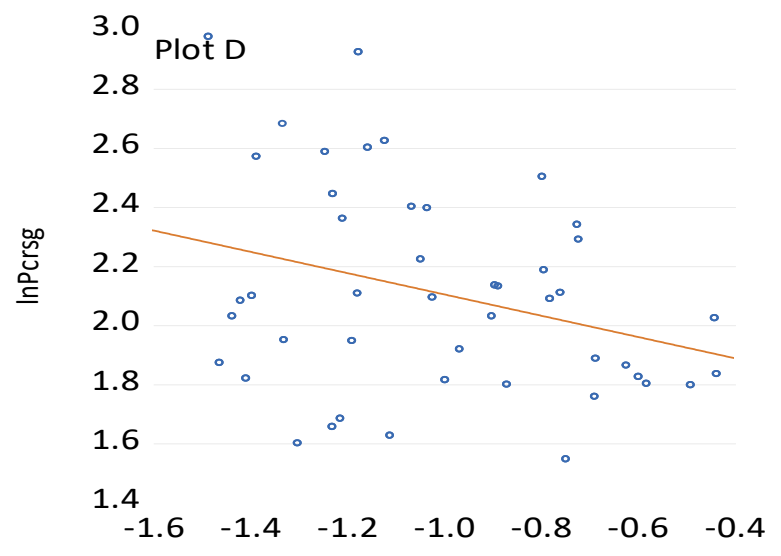

$\ln A$

InCEI shows the partial correlation between the key variables of interest, and the financial development in Nigeria. Plot A shows a strong positive correlations exists between affluence $(\ln A)$ and emissions ( $\operatorname{lnCO} 2$ ). Plot $\mathrm{B}$ shows that the partial correlation between carbon emission intensity $\ln (\mathrm{CEI})$ and fossil fuel consumption is positive. Plot $\mathrm{C}$ follows negative correlation between $\ln \mathrm{A}$ and lnFossil. In sum Plots $\mathrm{A}$, and $\mathrm{B}$ show that the energy consumption trend and economic structure in Nigeria could lead carbon intensive activities. Considering the negative correlation between the amount of $\mathrm{CO} 2$ emitted per unit of output $\ln (\mathrm{CEI})$ and the domestic credit to the private sector by banks, it therefore subject investigation into whether there is any significant relationship leading energy transition exist between bank credit to the private sector carbon emission in Nigeria economy. 
Table 3: Traditional unit root ADF

\begin{tabular}{|c|c|c|c|c|c|c|c|c|}
\hline \multirow[b]{2}{*}{ Variables } & \multicolumn{2}{|c|}{ Level form I(0) } & \multirow[b]{2}{*}{ break date } & \multicolumn{5}{|c|}{ First difference I(1) } \\
\hline & t-statistics & $\mathrm{p}$-value & & t-statistics & $\mathrm{p}$-value & break date & Decision & Result \\
\hline $\ln \mathrm{CEI}$ & -2.6716 & 0.2527 &. & $-6.7107 * * *$ & 0.0000 &. & Reject & $\mathrm{I}(1)$ at $1 \%$ \\
\hline $\ln \mathrm{CO} 2$ & -2.0933 & 0.5354 &.- & $-7.1173 * * *$ & 0.0000 &.- & Reject & $\mathrm{I}(1)$ at $1 \%$ \\
\hline $\ln \mathrm{P}$ & $-4.1621 * *$ & 0.0117 &.- & $-8.2699 * * *$ & 0.0000 &.- & Reject & $\mathrm{I}(0)$ at $5 \%$ \\
\hline $\ln \mathrm{A}$ & -1.3979 & 0.8455 &.- & $-4.9815^{* * *}$ & 0.0011 &.- & Reject & $\mathrm{I}(1)$ at $5 \%$ \\
\hline $\ln$ Pcrsg & -2.7466 & 0.2239 &.- & $-4.4133 * * *$ & 0.0058 &.- & Reject & $\mathrm{I}(1)$ at $1 \%$ \\
\hline lnFossil & -3.2174 & 0.0946 &.- & $-5.3377 * * *$ & 0.0004 &.$^{-}$ & Reject & $\mathrm{I}(1)$ at $1 \%$ \\
\hline $\ln$ Ecge & -2.8234 & 0.1968 &.- & $-5.4863 * * *$ & 0.0003 &.- & Reject & $\mathrm{I}(1)$ at $1 \%$ \\
\hline
\end{tabular}

590 Note:. $* * \& * * *$ indicate significance at $5 \%$ and $1 \%$ levels respectively

591 In table 3, to obtain the stationarity states of the variables of our model, we performed the

592 traditional unit root test of Augmented Dickey-Fuller test (ADF), and the Lee and Strazicich (2003)

593 Lagrange multiplier (LM). The ADF test examines the time series properties without accounting

594 for structural changes in the series but the second test does. Thus, both test reveal mixed

595 stationarity. That is, ADF test indicate that $\operatorname{lnCEI}(\log$ of carbon emission intensity), $\operatorname{lnCO} 2(\log$

596 of carbon dioxide emission), $\ln$ Pcrsg (log of private sector credit), $\ln$ Fossil (log of fossil energy)

597 and $\ln$ Ecge (log of economic globalization) were found the first difference stationary, which

598 implies the presence of unit root in the data while $\ln \mathrm{P}(\log$ of total population) and $\ln \mathrm{A}(\log$ of

599 GDP per capita) have no unit root and as such they are stationary at level. On the other hand, in

600 the table 4, the Lee and Strazicich (2003) Lagrange multiplier (LM) test shows that $\operatorname{lnCEI}, \operatorname{lnCO} 2$,

$601 \ln \mathrm{P}$ and $\operatorname{lnEcge}$ are all stationary at level while $\ln \mathrm{A}, \ln$ Pcrsg and $\operatorname{lnfossil}$ are only stationary when

602 difference at first difference.

603

604 Table 4: Unit root with two structural break: Lee Strazicich LM unit root test

\begin{tabular}{|c|c|c|c|c|c|c|c|}
\hline \multirow[b]{2}{*}{ variables } & \multicolumn{2}{|c|}{ Level form $\mathrm{I}(0)$} & \multirow[b]{2}{*}{ Result } & \multicolumn{4}{|c|}{ First difference I(1) } \\
\hline & t-statistics & break date & & t-statistics & break date & Decision & Result \\
\hline $\ln \mathrm{CEI}$ & $-7.2326 * * *$ & 19871999 & $\mathrm{I}(0)$ & $-7.2225 * * *$ & 19811990 & Reject & $\mathrm{I}(0)$ \\
\hline $\ln \mathrm{CO} 2$ & $-6.2208 * *$ & 19871998 & $\mathrm{I}(0)$ & $-7.7487 * * *$ & 19811995 & Reject & $\mathrm{I}(0)$ \\
\hline $\ln \mathrm{P}$ & $-18.412 * *$ & 19832002 & $\mathrm{I}(0)$ & $-18.593 * *$ & 19821987 & Reject & $\mathrm{I}(0)$ \\
\hline $\ln \mathrm{A}$ & -5.0419 & 19902010 & $\mathrm{I}(1)$ & $-6.6623 * *$ & 19912007 & Reject & $\mathrm{I}(1)$ \\
\hline $\ln$ Pcrsg & -5.3276 & 19841988 & $\mathrm{I}(1)$ & $-6.9498 * *$ & 19812006 & Reject & $\mathrm{I}(1)$ \\
\hline $\ln$ Fossil & -5.1474 & 19922009 & $\mathrm{I}(1)$ & $-6.9698 * *$ & 19812008 & Reject & $\mathrm{I}(1)$ \\
\hline $\ln$ Ecge & $-7.0857 * *$ & 19872003 & $\mathrm{I}(0)$ & $-7.2967 * * *$ & 19872007 & Reject & $\mathrm{I}(0)$ \\
\hline
\end{tabular}

Note:. ${ }^{* *} \& * * *$ indicate significance at $5 \%$ and $1 \%$ levels respectively 
608

609

610

611

612

613

614

615

616

617

618

619

620

621

622

623

624

625

626

627

628

\section{ARDL-bounds test for cointegration}

Table 5 shows the implementation of ARDL bounds test for cointegration that explores the longrun relationship among environmental indicators $(\ln \mathrm{CO} 2, \ln \mathrm{CEI})$, and the following explanatory variables: population $(\ln \mathrm{P})$, affluence $(\ln \mathrm{A})$, fossil energy intensity of consumption $(\operatorname{lnFossil})$, domestic credit to the private sector ( $\ln$ Fcrsg), and economic globalization ( $\ln$ Ecge). Kripfganz and Schneider (2019) provide P value, critical values, and the computed F and $\mathrm{T}$ statistics at the lower side of table 5. The optimum lags are based on the Akaike Information Criterion (AIC) and the presence of dummy variable is evidence of structural break in the system. The results show that calculated $\mathrm{F}$ and $\mathrm{T}$ have a significance level and are more than upper critical values $\mathrm{I}(1)$ at $1 \%$ level for both specifications, while the P values are below $0.001(\mathrm{p}<0.001)$. On the basis of these figures, in both specification suggesting co-integrating environmental indicators (CO2, CEI), population (P), income (A), fossil energy intensity (fossil), domestic credit to the private sector (Pcrsg), and economic globalization (Ecge) in Nigeria, the null of no co-integration hypothesis between the variables was denied. The two model from the ARDL do not have any econometric misspecifications, serial correlations, heteroscedasticity, non-normality, when subjected to various kinds of diagnostic test such as; Breush-Godfrey LM, Breusch-Pagan Godfrey, ARCH, Ramsey RESET, and Jarque-Bera (see table 5). Figure 6 and 7 are used to test the long run structural stability test using the CUSUM and CUSUMSQ test statistics as prescribed by Brown et al. (1975) and there is evidence of stability over the selected period in the two specification. 


\begin{tabular}{|c|c|c|c|c|c|}
\hline Model & Optimal Lag selection & $\mathrm{K}$ & TBrk & F statistics & $\mathrm{t}$ statistics \\
\hline $\operatorname{lnCO2}=f\{\ln P, \ln A, \ln P$ crsg, $\ln F$ ossil, $\ln E c g e\}$ & $\mathrm{AIC}=2$ & 5 & 19871998 & $8.7994 * * *$ & $-6.8605 * * *$ \\
\hline \multicolumn{6}{|l|}{ Diagnostic Tests: } \\
\hline Jarque-Bera Normality test & $2.3601[0.3072]$ & & & & \\
\hline BG serial correlation LM test & $0.9329[0.3341]$ & & & & \\
\hline Heteroskedasticity test: ARCH effect & $0.2893[0.5907]$ & & & & \\
\hline Ramsey RESET test & $1.9014[0.1797]$ & & & & \\
\hline Durbin-Watson statistic & 2.2033 & & & & \\
\hline $\ln C E I=f\{\ln P, \ln A, \ln P \operatorname{crs} g, \ln F o s s i l, \ln E c g e\}$ & $\mathrm{AIC}=2$ & 5 & 19871999 & $6.3082 * * *$ & $-5.7467 * * *$ \\
\hline \multicolumn{6}{|l|}{ Diagnostic Tests: } \\
\hline Jarque-Bera Normality test & $2.7839[0.2485]$ & & & & \\
\hline BG serial correlation LM test & $3.9902[0.1360]$ & & & & \\
\hline Heteroskedasticity test: ARCH effect & $2.1261[0.1448]$ & & & & \\
\hline Ramsey RESET test & $0.6335[0.5317]$ & & & & \\
\hline Durbin-Watson statistic & 1.9034 & & & & \\
\hline \multicolumn{6}{|l|}{ Critical values and $\mathrm{P}$ values } \\
\hline Source: Kripfganz and Schneider (2018) & $10 \%$ & $5 \%$ & $1 \%$ & p-value & \\
\hline F test: $\mathrm{I}(0)$ & 2.453 & 2.954 & 4.143 & 0.0000 & \\
\hline F test: $\mathrm{I}(1)$ & 3.739 & 4.405 & 5.974 & 0.0000 & \\
\hline T test: $\mathrm{I}(0)$ & -2.515 & -2.870 & -3.593 & 0.0000 & \\
\hline T test: $\mathrm{I}(1)$ & -3.823 & -4.246 & -5.101 & 0.0000 & \\
\hline \multicolumn{6}{|c|}{$\begin{array}{l}\text { Note: The asterisks * and } * * \text { indicate } 1 \% \text { and } 5 \% \text { significance levels, respectively based on the critical values generated by the bound testing } \\
\text { procedure. Akaike information criteria (AIC) is the optimal lag length. The F-statistic follows the asymptotic critical bounds, which is } \\
\text { generated from the Kripfganz and Schneider (2019) procedure. }\end{array}$} \\
\hline
\end{tabular}


Table 6: Estimates for Carbon emission intensity $(\ln \mathrm{Co} 2)$

\begin{tabular}{|c|c|c|c|c|c|c|c|c|}
\hline \multirow[b]{2}{*}{ Variable } & \multicolumn{4}{|l|}{ ARDL } & \multirow[b]{2}{*}{ Coefficient } & \multicolumn{3}{|c|}{ Dynamic ARDL } \\
\hline & Coefficient & Std. Error & $\mathrm{t}$-Statistic & Prob. & & Std. Error & t-Statistic & Prob. \\
\hline \multicolumn{9}{|c|}{ Panel A: short-run estimate } \\
\hline ecm $(-1)$ & $-0.4636 * * *$ & 0.1112 & -4.1696 & 0.0003 & $-0.4391 * * *$ & 0.1165 & -3.7700 & 0.0010 \\
\hline$\Delta \ln \mathrm{P}$ & -2.5471 & 71.943 & -0.4107 & 0.6845 & $-1.5487^{* *}$ & 35.399 & -2.9300 & 0.0060 \\
\hline$\Delta \ln \mathrm{A}$ & $2.1524^{* * *}$ & 0.5806 & 3.7071 & 0.001 & $2.0801 * * *$ & 0.5872 & 3.5400 & 0.0010 \\
\hline$\Delta \ln$ Pcrsg & -0.0090 & 0.1293 & -0.0699 & 0.9448 & -0.0348 & 0.1351 & -0.2600 & 0.7990 \\
\hline$\Delta \ln$ Fossil & $1.2387^{* *}$ & 0.3839 & 3.2271 & 0.0033 & $0.9226^{* *}$ & 0.3809 & 2.4200 & 0.0210 \\
\hline$\Delta \ln \mathrm{Ecg}$ & $2.4425^{* * *}$ & 0.5739 & 4.2563 & 0.0002 & $2.0042^{* * *}$ & 0.5537 & 3.6200 & 0.0010 \\
\hline$\Delta$ (TBrk) & $-0.3049 * *$ & 0.1170 & -2.6063 & 0.0147 & $-0.2635^{* *}$ & 0.1197 & -2.2000 & 0.0350 \\
\hline \multicolumn{9}{|c|}{ Panel B: long run coefficients } \\
\hline C & 521.581 & 413.841 & 1.2603 & 0.2183 & 4.3883 & 2.8204 & 1.5600 & 0.1300 \\
\hline $\ln \mathrm{P}$ & -2.9362 & 23.0889 & -1.2099 & 0.2368 & $-0.7527 * *$ & 0.2618 & -2.8800 & 0.0070 \\
\hline $\ln A$ & $2.2852^{* * *}$ & 0.6176 & 3.7003 & 0.001 & $0.9504 * *$ & 0.3846 & 2.4700 & 0.0190 \\
\hline $\ln$ Fossil & 1.0864 & 0.6454 & 1.6835 & 0.1038 & $0.4375^{* * *}$ & 0.2102 & 2.0800 & 0.0460 \\
\hline $\ln$ Pcrsg & $0.7940 * *$ & 0.3383 & 2.3471 & 0.0265 & $0.2391 *$ & 0.1404 & 1.7000 & 0.0990 \\
\hline $\ln$ Ecge & 5.2686 & 1.2750 & 4.1323 & 0.0003 & $2.1466 * *$ & 0.6590 & 3.2600 & 0.0030 \\
\hline Adj. R squared & 0.893 & & & & 0.7292 & & & \\
\hline Simulations & & & & & 5000 & & & \\
\hline P-value of F stat & 0.0000 & & & & 0.0000 & & & \\
\hline
\end{tabular}

638 Note: * and ** respectively show significance at $1 \%$ and 5\% levels.

639

640

641

642

643

644 
645 Table 7: Estimates for Carbon emission intensity (lnCEI)

\begin{tabular}{|c|c|c|c|c|c|c|c|c|}
\hline \multirow[b]{2}{*}{ Variable } & \multicolumn{4}{|l|}{ ARDL } & \multirow[b]{2}{*}{ Coefficient } & \multicolumn{3}{|c|}{ Dynamic ARDL } \\
\hline & Coefficient & Std. Error & t-Statistic & Prob. & & Std. Error & t-Statistic & Prob. \\
\hline \multicolumn{9}{|c|}{ Panel A: short-run estimate } \\
\hline ecm(-1) & $-0.4062 * * *$ & 0.1044 & -3.8925 & 0.0006 & $-0.3673 * * *$ & 0.1097 & -3.3500 & 0.0020 \\
\hline$\Delta \ln \mathrm{P}$ & -1.2676 & 66.9147 & -0.2431 & 0.8097 & $-1.3662 * *$ & 32.986 & -3.2500 & 0.0030 \\
\hline$\Delta \ln \mathrm{A}$ & 0.9542 & 0.5454 & 1.7497 & 0.0911 & 0.9091 & 0.5559 & 1.6400 & 0.1120 \\
\hline$\Delta \ln \mathrm{Pcrsg}$ & 0.0151 & 0.1195 & 0.1260 & 0.9006 & 0.0441 & 0.1266 & 0.3500 & 0.7300 \\
\hline$\Delta \ln$ Fossil & $1.3763 * *$ & 0.3573 & 3.8515 & 0.0006 & $1.0418^{* *}$ & 0.3536 & 2.9500 & 0.0060 \\
\hline$\Delta \ln \mathrm{Ecg}$ & $1.4461^{* *}$ & 0.5284 & 2.7369 & 0.0107 & $1.3973^{* *}$ & 0.5049 & 2.7700 & 0.0090 \\
\hline$\Delta$ (TBrk) & -0.1511 & 0.1139 & -1.3267 & 0.1953 & -0.1422 & 0.1189 & -1.2000 & 0.2410 \\
\hline \multicolumn{9}{|c|}{ Panel B: long run coefficients } \\
\hline c & 129.798 & 419.048 & 0.3097 & 0.7590 & $9.6053 * *$ & 2.9302 & 3.2800 & 0.0030 \\
\hline $\ln \mathrm{P}$ & -8.7053 & 23.3800 & -0.3723 & 0.7124 & $-1.0047^{* *}$ & 0.3087 & -3.2500 & 0.0030 \\
\hline $\ln \mathrm{A}$ & $1.7908 * *$ & 0.6422 & 2.7886 & 0.0094 & $0.5587^{*}$ & 0.2913 & 1.9200 & 0.0640 \\
\hline $\ln$ Fossil & $0.8008 * *$ & 0.3553 & 2.2541 & 0.0322 & $0.4751 * *$ & 0.1962 & 2.4200 & 0.0220 \\
\hline $\ln$ Pcrsg & $1.9659 * *$ & 0.6541 & 3.0055 & 0.0055 & $0.2725^{* *}$ & 0.1311 & 2.0800 & 0.0460 \\
\hline $\ln \mathrm{Ecg}$ & $3.5599 * *$ & 1.1811 & 3.0141 & 0.0054 & $1.3613 * *$ & 0.6534 & 2.0800 & 0.0460 \\
\hline Adj. R squared & 0.8287 & & & & 0.7559 & & & \\
\hline Simulations & & & & & 5000 & & & \\
\hline P-value of F-stat & 0.0000 & & & & 0.000 & & & \\
\hline
\end{tabular}

Note: * and ${ }^{* *}$ respectively show significance at $1 \%$ and $5 \%$ levels. 


\section{Dynamic ARDL simulation results}

649 For comparative analysis, we started by applying the traditional ARDL analysis and then followed by the dynamic ARDL model simulations. The empirical evidence in Table $6 \& 7$ confirm the presence of common relationship in terms positive or negative signs between the endogenous and exogenous variables, however, their measurements varies. To provide a robust estimates, a multivariable normal distribution vector is provided by 5000 simulations. Table $6 \& 7$ show the model estimates of aggregate carbon dioxide (CO2) emission and carbon emission intensity (CEI) respectively. The dynamic ARDL simulations observed at 10 times point with positive or negative 10 percent innovations on each of the exogenous variables in the model reflect graphical representation in figures $8,9,10,11,12,13$ and 14 to cause counterfactual changes in the independent. Table 6 we found that bank credit to the private sector $(\ln \mathrm{Pcrsg})$ is positively linked to carbon emissions in the long run at the $10 \%$ level. This implies that (lnPcrsg) plays a significant role in increasing carbon emissions. All other being equal, a 1\% increase in bank credit to the private sector leads carbon emissions by $0.2391 \%$. However in the short run, bank credit to the private sector ( $\ln$ Pcrsg) is statistically insignificant. Figure 8 indicates the impact of positive or negative $10 \%$ change in predicted $\ln$ Pcrsg on $\ln \mathrm{CO} 2$. A positive $10 \%$ change in the first graph produced an insignificant influence in $\ln \mathrm{CO} 2$ in the short-run, however, the influence shows a significant increase in the predicted long-run value. In the second graph a negative $10 \%$ change produced an insignificant rise in $\ln \mathrm{CO} 2$ in the short-run. The long-run influence has a significant increase in the predicted value, but the influence in the long run decreased. Thus, positive change is high compared to the effect of negative change in $\ln \mathrm{CO} 2$.

Similarly in Table 7, bank credit to the private sector (lnPcrsg) increases carbon intensity in the long run. All else equal, $0.27 \%$ of carbon intensity is led by $1 \%$ increase in bank credit to the private sector. However, bank credit to the private sector (lnPcrsg) is statistically insignificant in the short run. Figure 9 indicates the influence of positive or negative 10\% change in predicted $\ln$ Pcrsg on $\ln$ CEI. In the first graph a positive $10 \%$ change produced an insignificant influence on carbon intensity in the short-run, however, the impact shows a significant increase in the predicted long-run value. Conversely, the second graph shows that a negative $10 \%$ change produced an insignificant increase in carbon intensity in the short-run. In the long-run, the value had a 
677 significant increase in the predicted value, but the effect in the long run decrease. Thus, the impact 678 of positive change is high compared to the impact of negative change in carbon intensity. 679 Therefore, financial development is attached to negative environmental consequences as it creates 680 more carbon emissions. This implies that financial development harms the environment by 681 incrementing financial channels, increasing investments in new projects, (Haseeb et al. 2018). 682 Indeed, the growing level of $\mathrm{CO} 2$ emissions is corroborated with the findings (Asumadu-Sarkodie 683 and Owusu, 2016, Shen et al. 2020, Khan, Ju, Latif and Khan 2020, Saud, Chen and Haseeb, 2020).

684 The empirical results for long-run impact of population, economic growth, fossil consumption 685 power intensity and economic globalization are reported in table 6. The impact of population on 686 carbon emissions $(\operatorname{lnCO} 2)$ is negative and significant. This shows that population is declining 687 carbon emissions. It implies that population is associated with higher income levels which serve 688 as a determinant factors in demanding a friendly ecosystem that reduces carbon emission. Keeping 689 other factors constant, $1 \%$ increase in $\ln \mathrm{P}$ lowers carbon emissions by $1.5 \%$ in the short-run and 6900.75 percent in the long-run. Economic growth (affluence) is positively linked to carbon emissions $691(\operatorname{lnCO} 2)$ at 1 percent level. It implies that a $1 \%$ increase in economic growth may lead carbon 692 emissions by 2.0801 percent in the short-run and 0.9504 percent in the long-run keeping all else 693 the same.

694 695 696 697 698 699 700 701 702 703 704 705 706

We found evidence of inverted U-shaped relationship between carbon emission and economic growth by comparing the short-run and long-run economic growth, the long-run effect of economic growth is found to be smaller than the short-run impact. This result is consistent with Narayan and Narayan (2010), who predicted the EKC hypothesis through the same procedure. Figure 10 explains the effect of 10 positive and negative shocks on aggregate $\mathrm{CO} 2$ emissions (lnCO2) in expected economic growth value $(\ln \mathrm{A})$. The first graph shows that positive $10 \%$ shocks created a substantial short-run increase in aggregate $\mathrm{CO} 2$ emissions, and the effect stayed unchanged in the long-run. A negative $10 \%$ innovation is linked to positive effect in short-run aggregate $\mathrm{CO} 2$ emissions, and the influence in long-run value produced a significant increase in the expected value. Even, long-term impact decreased.

In table 6, fossil energy intensity of consumption increases aggregate $\mathrm{CO} 2$ emissions significantly at $1 \%$ level of significance. A $0.9226 \%$ and $0.4375 \%$ of aggregate $\mathrm{CO} 2$ emissions is increased due to $1 \%$ rise in fossil energy intensity of consumption in the short-run and long-run leading to 
environmental degradation through high carbon emissions. This findings is in consonance with the conclusion from Lin and Agyeman (2020). Figure 11 shows how positive and negative 10\% innovation in the predicted value of $\ln$ Fossil impact $\ln \mathrm{CO} 2$. The positive shock of fossil energy is stable in the long term, even though it increases $\mathrm{CO} 2$ emissions in the short term. On the other hand, the negative shocks in Infossil produced a significant positive impact on aggregate carbon emissions in the short-run and the effect in the long run remained stable and unchanged.

In Table 7, shows the short-run and long-run positive effect of lnfossil on carbon emission intensity at $1 \%$ level. It implies that a $1 \%$ increase in lnfossil may lead carbon emission intensity by $1.048 \%$ in the short-run and by $0.4751 \%$ in the long-run keeping all else unchanged. Figure 12 reveals the positive and negative shocks in lnfossil resulting to a changes carbon emission intensity (lnCEI). In the first plot, the positive shock of lnfossil is stable in the long run, even though it increases carbon emission intensity in the short term, while the second plot produced a significant positive impact on carbon emission intensity in the short-run. The effect also had a significant predicted long-run value. Figure 13 indicates the positive and negative changes in economic globalization and its impact on Nigeria's $\mathrm{CO} 2$ emissions. $10 \%$ positive change in economic globalization suggests a positive effect on the $\mathrm{CO} 2$ emissions in Nigeria both in the short run and in the long run. This could be attribute to the rising trade and investment activities, leading to a higher amount of energy usage required in the production and consumption activities, which eventually release more carbon dioxide into the environment. Meanwhile, a $10 \%$ negative change in economic globalization indicates a positive effect on $\mathrm{CO} 2$ emissions in the short run. In the long run, $\mathrm{CO} 2$ emissions decrease with a decrease in economic globalization. Overall the estimates from this empirical study regarding the impact of economic growth and fossil energy consumption align with the theoretical expectations and existing empirical findings. Past empirical entries such as Letcher (2020) believed that the rise of carbon dioxide in the atmosphere is as a result of increased activities from economic growth and fossil energy consumption. For instance, a longrun decrease in the $\mathrm{CO} 2$ emissions could be from a decrease in the economic globalization.

The deviation from the short run equilibrium is corrected through the negative and statistical significant of the coefficient of ecm $(-1)$ in both specifications. In Table 6 , the coefficient -0.4391 indicates that approximately $43.91 \%$ of short-run deviation converges to a long run stable state. 
Table 7 shows that the significant negative coefficient suggests that roughly 37 percent of a shortterm disequilibrium is reversed to the long run in the carbon emission intensity model.

\section{Conclusion and policy implication}

The world has undergone a significant increase in carbon dioxide emissions, which harm the living conditions for the households. This tremendous concern for environmental pollution has led academics and environmental policymakers to focus on this issue to find suitable solutions and implement convenient policies. In this study, we contribute to the existing literature on the link between financial development and $\mathrm{CO} 2$ emissions. This study drew insight from the case of Nigeria by exploring the impact of bank credit to private sector on carbon emission over the period of 1971 to 2016. The model incorporated the impact of fossil energy intensity of consumption, bank credit to the private sector and economic globalization in the Stochastic Impact Regress on Population, Affluence and Technology (STIRPAT) Framework. In the analysis, the ARDL test confirmed the long-run equilibrium of these parameters over the sampled period in Nigeria. Using the dynamic ARDL model simulations, the results found are as follows: First, implication of the positive association between financial development and carbon dioxide in Nigeria can be attributed to the fact that availability of financial facilities stimulates expansion of economic activities which brings about high demand for energy consumption-goods that causes carbon dioxide emission in turn. This findings support the assertion by Al-Mulali, Saboori, and Ozturk. 2015, who observed that bank credits make possible loan facilities which encourages high demand for luxury goods and energy consumption goods and as such leads to air pollution by means of $\mathrm{CO} 2$ emission. Also, this should be guide to policy makers to make policies that are environmental friendly by advising the financial sectors to pursue giving loans to low-carbon projects and investment. Financial stability is a long term goal and that is why it is not significant in the short period. Direct relationship between GDP per capita and environmental degradation could be linked to the assertion that rise GDP entails rise in national income, and when this happens in a nation, the country will be in danger of high pollution especially when there is lack of energy conservation policy. This implies that Nigeria still uses obsolete equipment and relies heavily on non-renewable energy sources which causes the GHS emission thereby degrading the environment. In order to produce and at same time maintain environmental quality, government should encourage 
Figure 6: Equation 7 - CUSUM and CUSUMSQ for $\mathrm{CO} 2$ reduce carbon emission.

manufacturing industries by subsidizing the use of energy efficient equipment in production. Energy intensity having positive influence on $\mathrm{CO} 2$ implies that Nigeria relies heavily on nonrenewable energy sources such as coal and other energy sources which emits greenhouse gasses because of its emerging economy nature. It is due to infant industries in the country using obsolete and poor energy consumption technology that hampers the environment. Government can achieve tackle this problem by making subsidies available on low carbon technologies to encourage the use of renewable energy technology and as same time impose high tax on fossil fuel consumption in Nigeria beyond a certain threshold. this relationship is necessitated developing economies like Nigeria will find it very hard to stop energy use since it is the key input for production of goods and services such as; services industries, home utilities whose actions emits carbon into the environment. This outcome corroborates the findings of Haseeb et al. (2018) for and BRICS, Shahbaz et al. (2018) for Japan. Thus government should strive for the enhancement of energy efficiency via advanced and energy-efficient technologies. Positive linkage between globalization and $\mathrm{CO} 2$ emission indicates that Nigeria has not been able to attract high technological investment from abroad which provides access to advanced energy-efficient technologies which will help

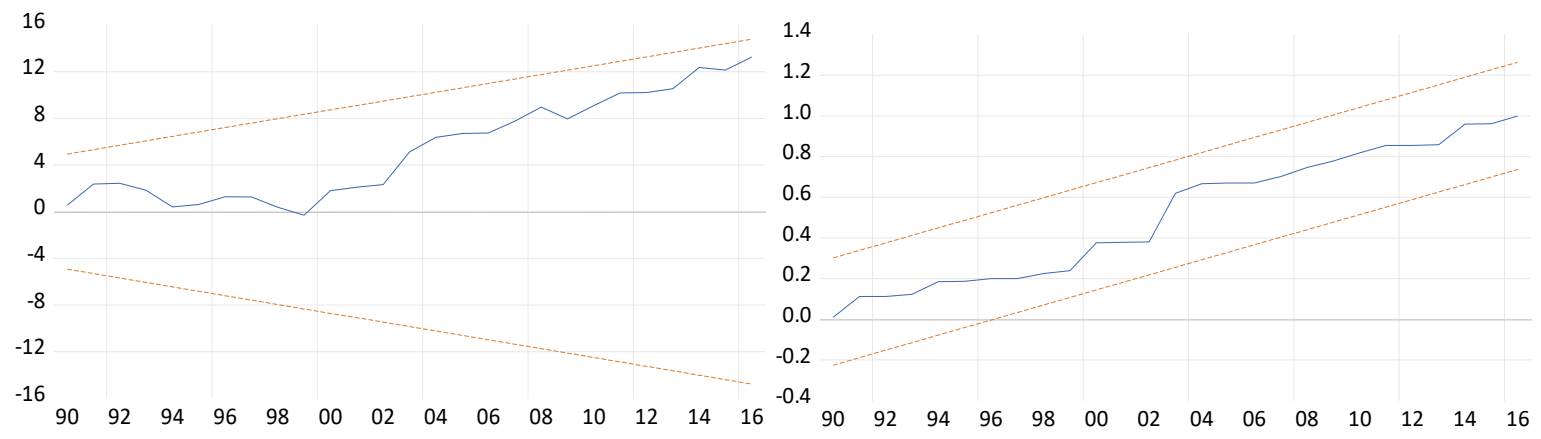




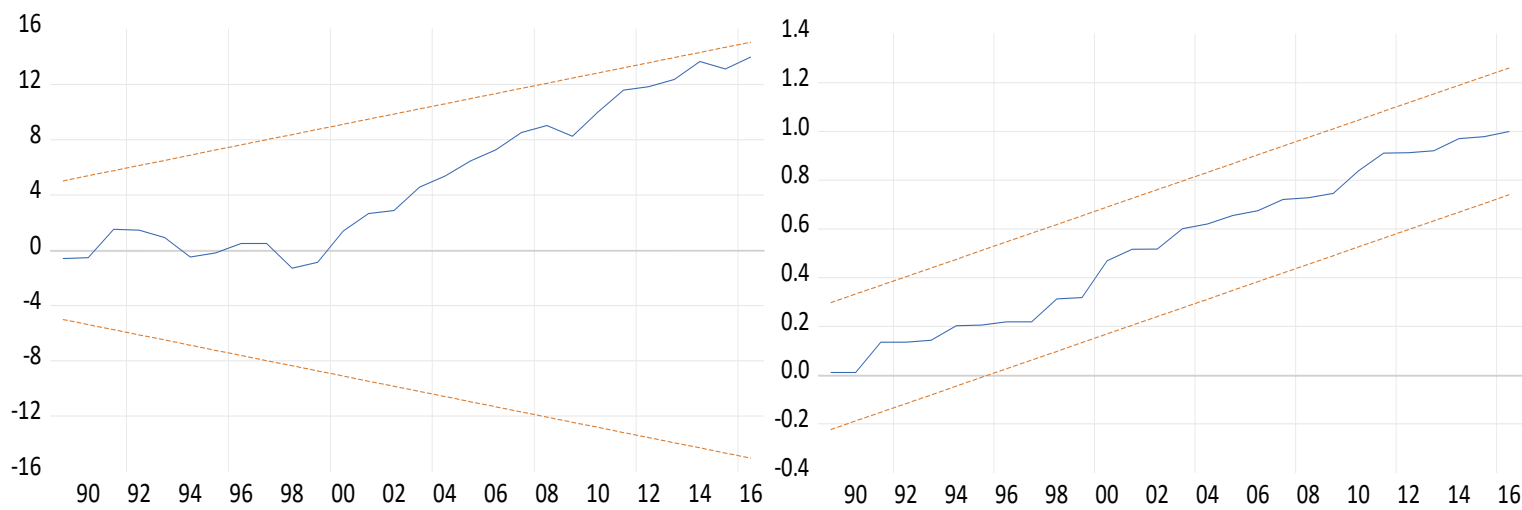

785

— CUSUM -.... $5 \%$ Significance

_ CUSUM of Squares $\ldots . . .5 \%$ Significance

Figure 7: Equation 8- CUSUM and CUSUMSQ for CO2

787
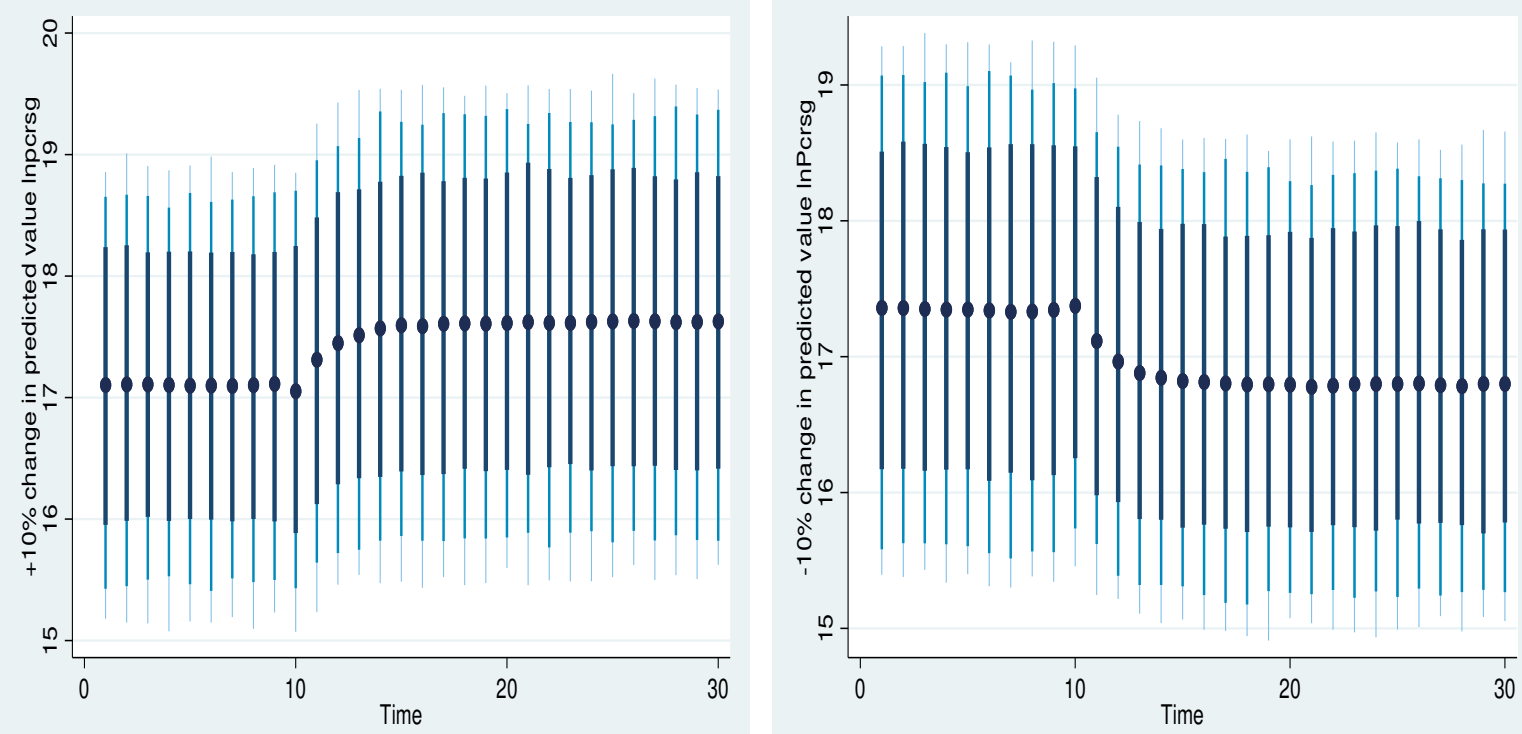

Figure 8 positive or negative $10 \%$ innovation in predicted $\ln$ Pcrsg on $\operatorname{lnCO} 2$. The dots and dark blue to 790 light blue lines explain average predicted value and $75 \%, 90 \%$, and $95 \%$ confidence intervals respectively 

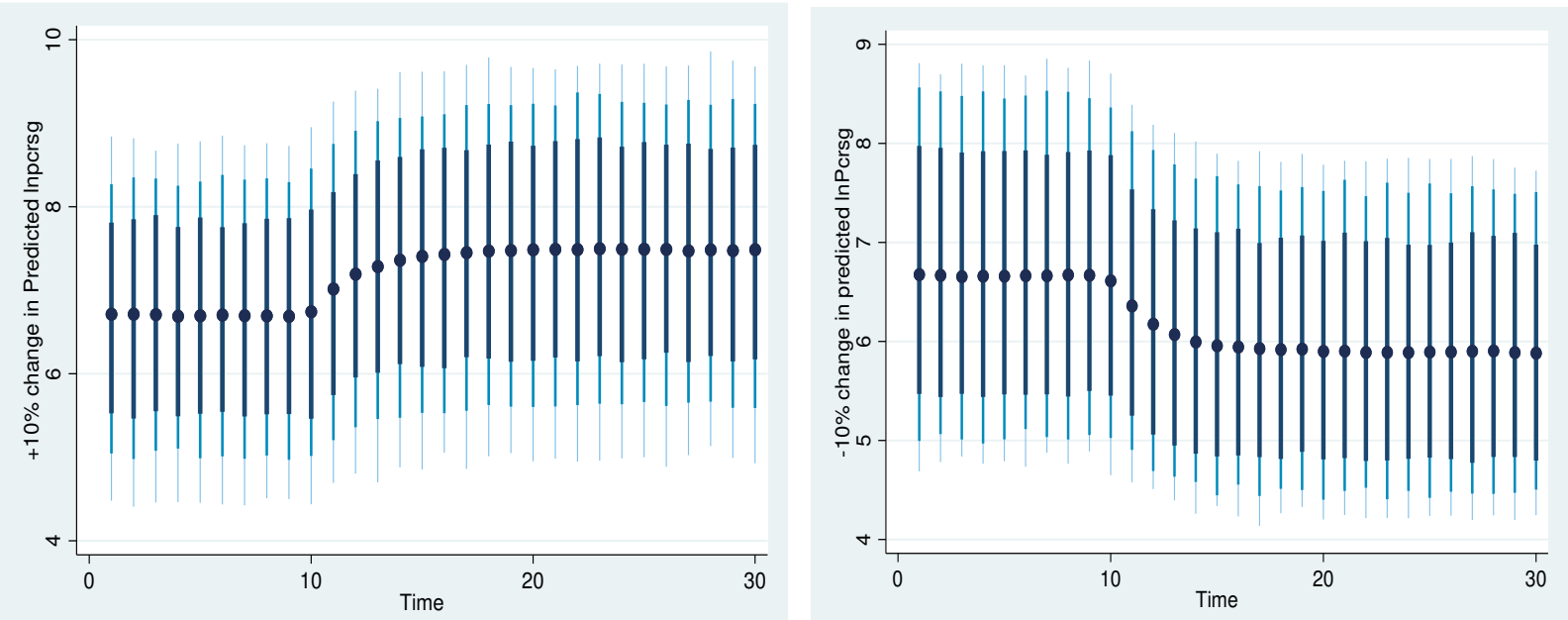

793

794

795

Figure 9 positive or negative $10 \%$ innovation in predicted $\ln$ Pcrsg on $\operatorname{lnCEI}$. The dots and dark blue to light blue lines explain average predicted value and 75\%,90\%, and 95\% confidence intervals respectively
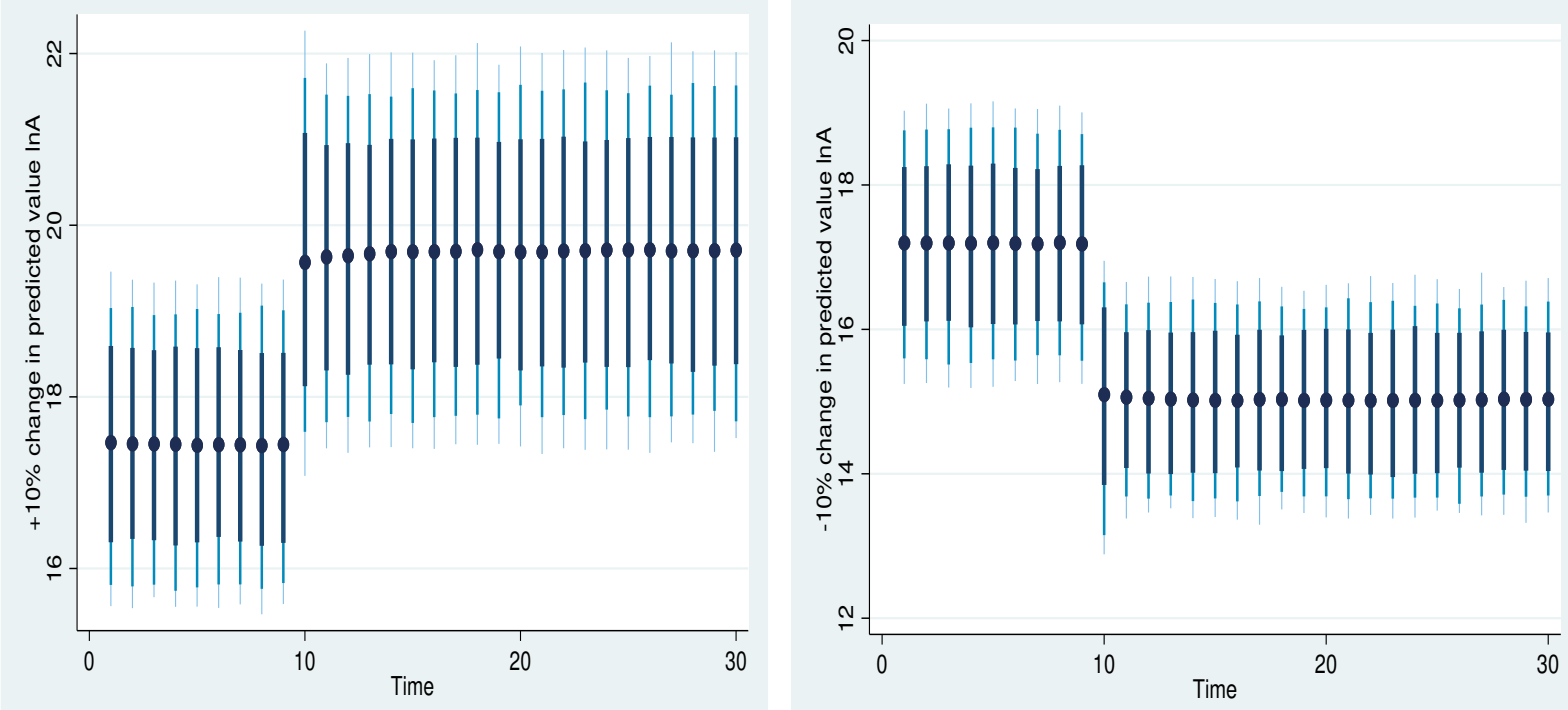

796

Figure 10: positive or negative $10 \%$ innovation in predicted $\ln \mathrm{A}$ on $\operatorname{lnCO} 2$. The dots and dark blue to light blue lines explain average predicted value and $75 \%, 90 \%$, and $95 \%$ confidence intervals respectively 

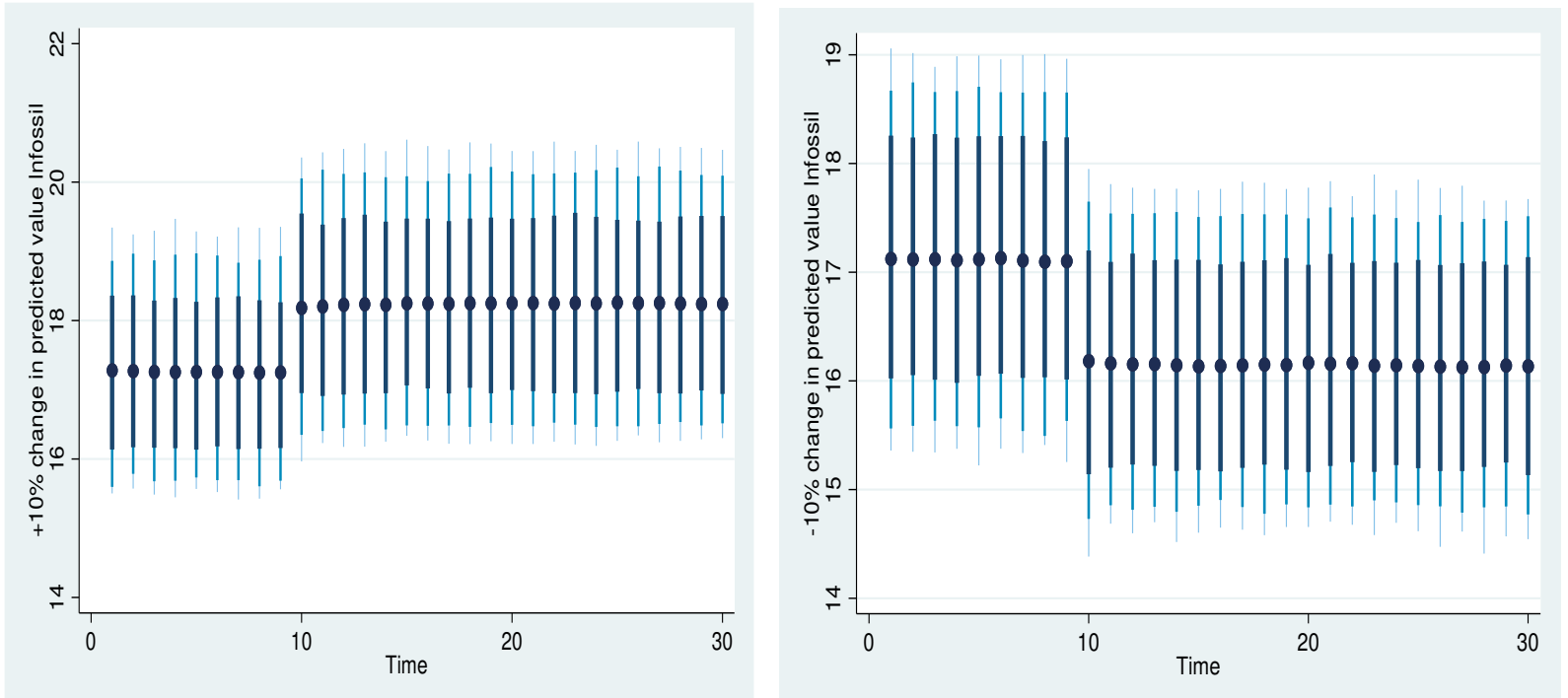

802

803

804

805

Fig. 11 positive or negative $10 \%$ innovation in predicted $\operatorname{lnFossil}$ on $\operatorname{lnCO} 2$. The dots and dark blue to light blue lines explain average predicted value and $75 \%, 90 \%$, and $95 \%$ confidence intervals respectively

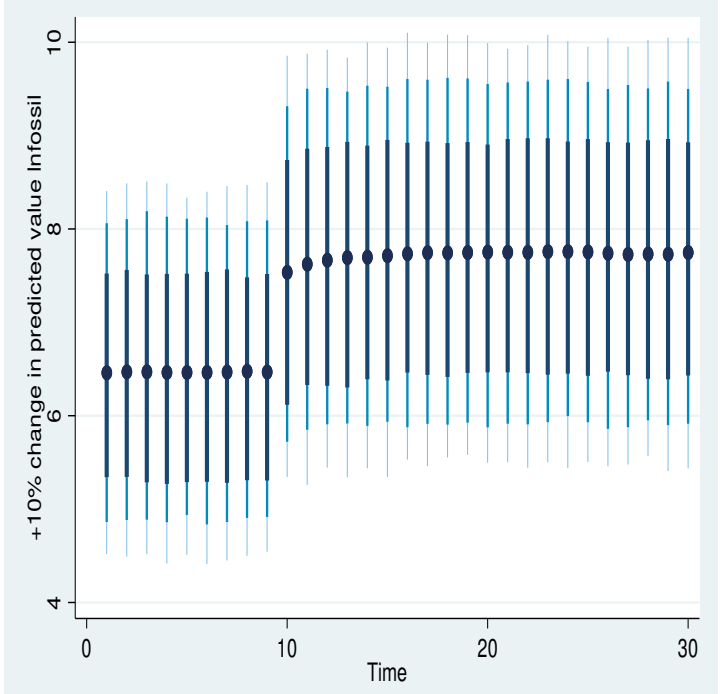

806

807

808

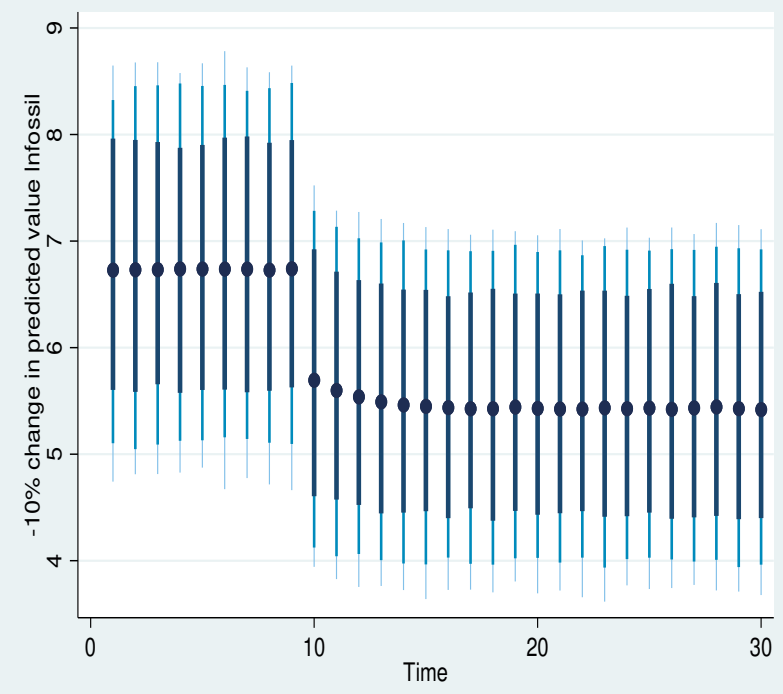

Fig. 12 positive or negative $10 \%$ innovation in predicted lnFossil on lnCEI. The dots and dark blue to light blue lines explain average predicted value and $75 \%, 90 \%$, and $95 \%$ confidence intervals respectively 

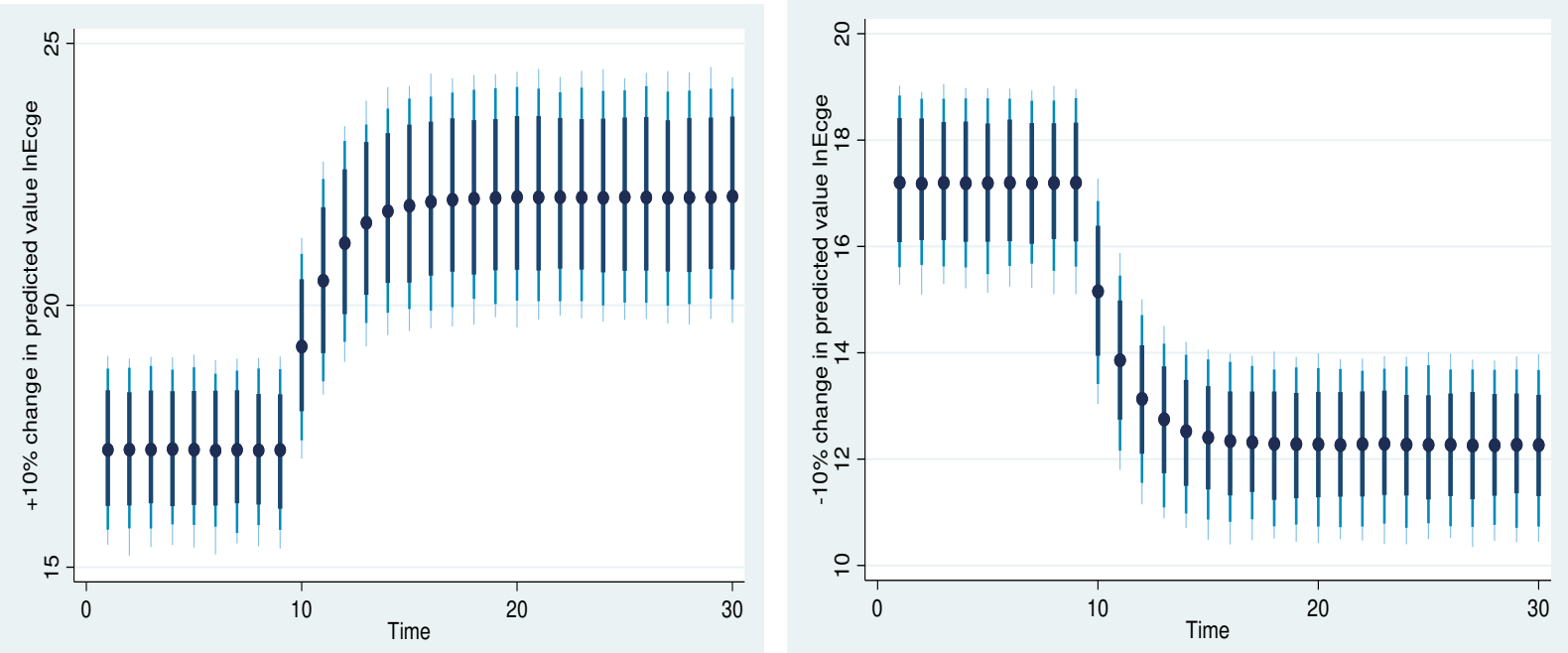

809

810

811

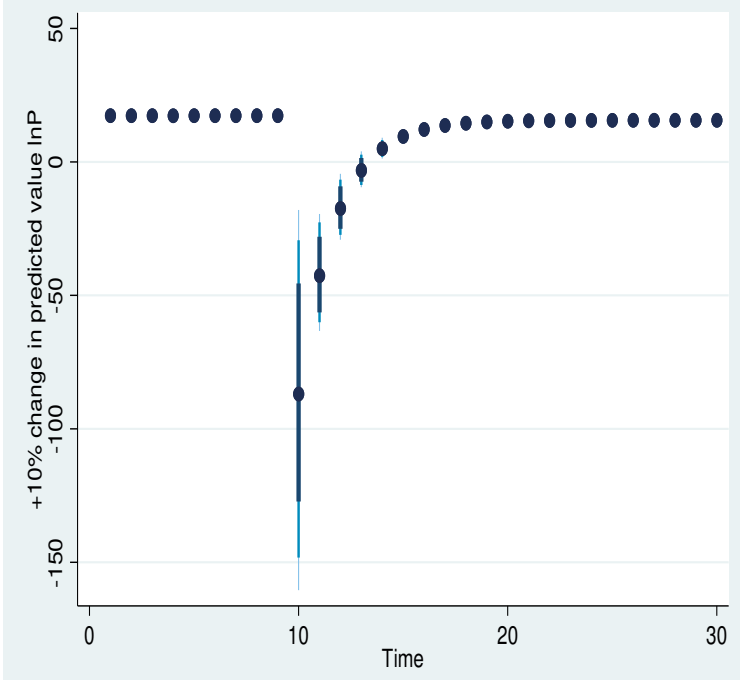

Figure 13: positive or negative $10 \%$ innovation in predicted lnEcge on $\operatorname{lnCO} 2$. The dots and dark blue to light blue lines explain average predicted value and 75\%, 90\%, and 95\% confidence intervals respectively

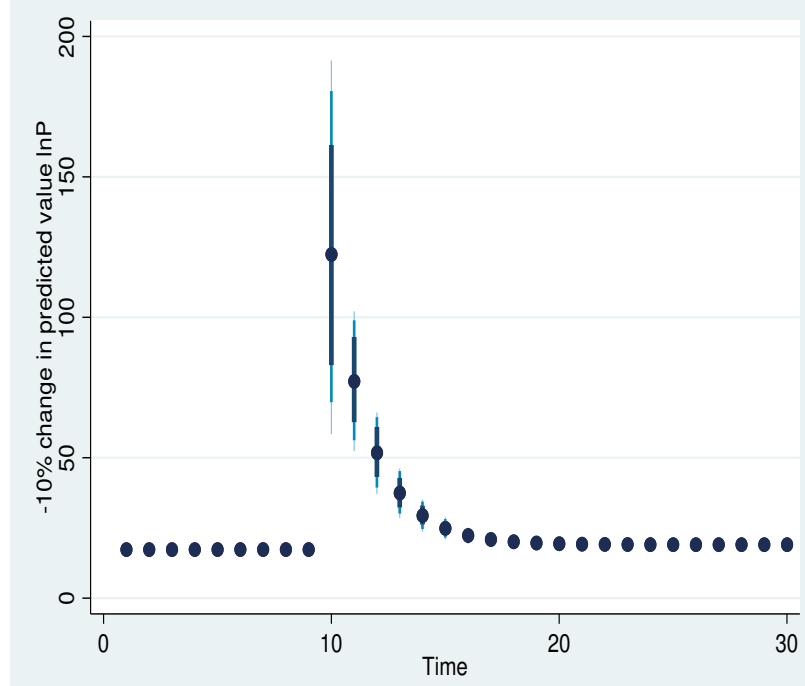

812

813

814

815

816

817

818

819

820
Figure 14: positive or negative $10 \%$ innovation in predicted $(\mathrm{lnP})$ on $\operatorname{lnCO} 2$. The dots and dark blue to light blue lines explain average predicted value and 75\%,90\%, and 95\% confidence intervals respectively 
821

822

823

824

825

826

827

828

829

830

831

832

833

834

835

836

837

838

839

840

841

842

843

844

845

846

847

848

849 
Appendix 1

851 Appendix 2: Total energy supply (TES) by source, Nigeria 1990-2018

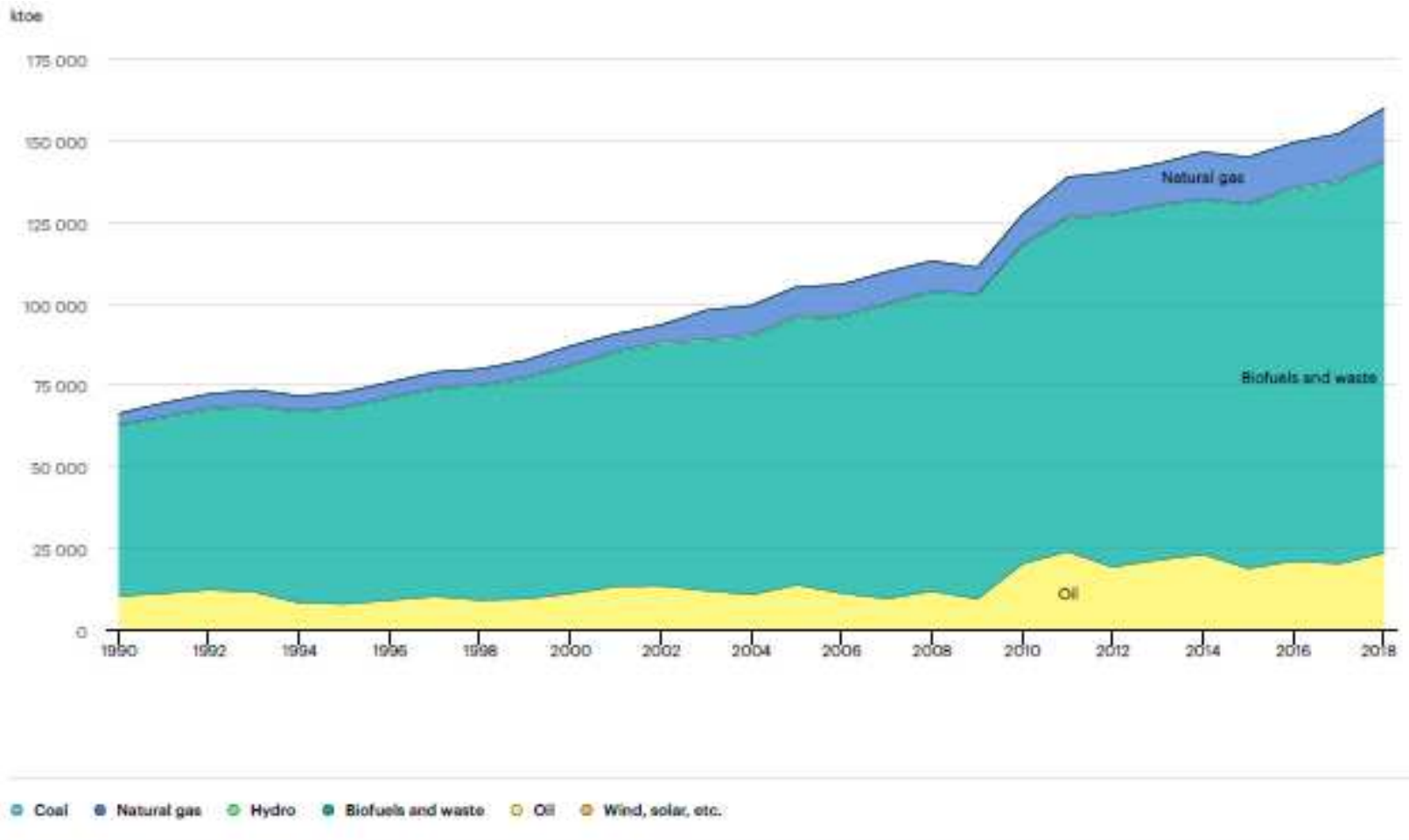

853 Source: IEA World Energy Balances 2020

854

855

856

857

858

859

860

861

862

863

864

865

866 
868 Declarations

869 Ethics approval and consent to participate

870 Note applicable

871 Consent for publication

$872 \quad$ Note applicable

873 Availability of data and materials

$874 \quad$ Note applicable

875 Competing interests

876 On behalf of all authors, the corresponding author states that there is no conflict of interest

877 Note applicable

$878 \quad$ Funding

879 Note applicable

880 Availability of data and material

$881 \quad$ Yes

882

883

884

885

886

887

888

889

890 
905

906

907

908 References

909 Abbasi, M. A., Parveen, S., Khan, S., \& Kamal, M. A. (2020). Urbanization and energy consumption effects 910 on carbon dioxide emissions: evidence from Asian-8 countries using panel data analysis. Environmental Science and Pollution Research, 1-15.

912 Adejumo, A.V, \& Asongu, S.A. (2020). Foreign direct investment, domestic investment and green growth 913 in Nigeria: any spillovers? In: International Business, Trade and Institutional Sustainability. 914 Springer Nature, Switzerland, 839-861. https://doi.org/10.1007/978-3-030-26759-9_50 
Adejumo, O.O. (2020). Openness and Greenness: Pay-Offs or Trade-Offs for the Nigerian Economy. In: International Business, Trade and Institutional Sustainability. Springer Nature, Switzerland, pp 863-886. https://doi.org/10.1007/978-3-030-26759-9_51

AhAtil, A., Bouheni, F. B., Lahiani, A., \& Shahbaz, M. (2019). Factors influencing CO2 emission in China: a nonlinear autoregressive distributed lags investigation. Online at https://mpra.ub.uni$\underline{\text { muenchen.de/91190/ }}$

Ahmad, M., Khan, Z., Ur Rahman, Z., \& Khan, S. (2018). Does financial development asymmetrically affect $\mathrm{CO} 2$ emissions in China? An application of the nonlinear autoregressive distributed lag (NARDL) model. Carbon Management, 9(6), 631-644.

Ali, H. S., Law, S. H., Lin, W. L., Yusop, Z., Chin, L., \& Bare, U. A. A. (2019). Financial development and carbon dioxide emissions in Nigeria: evidence from the ARDL bounds approach. GeoJournal, 84(3), 641-655.

Ali, H.S., Law, S.H., Zannah, T.I. (2016). Dynamic impact of urbanization, economic growth, energy consumption, and trade openness on $\mathrm{CO} 2$ emissions in Nigeria. Environ SciPollut Res 23(12):12435-12443

Al-Mulali, U., Saboori, B., \& Ozturk, I. (2015). Investigating the environmental Kuznets curve hypothesis in Vietnam. Energy Policy, 76, 123-131.

Amaral, L.F., Delaqua, G.C.G., Nicolite, M., Marvila, M.T., Azevedo, A.R.G., Alexandre, J., Vieira, C.M.F., \& Monteiro, S.N. (2019) Eco-friendly mortars with addition of ornamental stone wasteA mathematical model approach for granulometric optimization. Journal of Cleaner Production. https://doi.org/10.1016/j.jclepro.2019.119283.

Amin, A., Dogan, E., \& Khan, Z. (2020). The impacts of different proxies for financialization on carbon emissions in top-ten emitter countries. The Science of the Total Environment, 740, 140127-140127.

Aminu, H.J., Suraya, M, Ali, U. A, Ibrahim, S.F. \& Umar, A. M. (2020). Financial Development and the quality of the environment in Nigeria: An application of Non-Linear ARDL Aproach. Research in World Economy. 11 (1) 78-92. https://doi.org/10.5430/rwe.v11n1p78

Ashraf, N., Comyns, B., Tariq, S., \& Chaudhry, H. R. (2020). Carbon performance of firms in developing countries: The role of financial slack, carbon prices and dense network. Journal of Cleaner Production, 253, 119846.

Asumadu-Sarkodie, S., \& Owusu, P. A. (2016). Energy use, carbon dioxide emissions, GDP, industrialization, financial development, and population, a causal nexus in Sri Lanka: With a 
subsequent prediction of energy use using neural network. Energy Sources, Part B: Economics, Planning, and Policy, 11(9), 889-899.

Aye, G.C. \& Edoja, P.E. (2017), Effect of economic growth on C02 emission in developing countries: Evidence from a dynamic panel threshold model. Cogent Economics and Finance, 5(1), 1-22.

Azevedo, A.R.G., Marvila, T.M., Fernandes, W.J., Alexandre, J., Xavier, G.C., Zanelato, E.B., Cerqueira, N.A., Pedroti, L.G. \& Mendes, B.C. (2019) Assessing the potential of sludge generated by the pulp and paper industry in assembling locking blocks. Journal of Building Engineering. 23(2019); 334-340. https://doi.org/10.1016/j.jobe.2019.02.012.

Ben-Iwo, J., Manovic, V., \& Longhurst, P. (2016). Biomass resources and biofuels potential for the production of transportation fuels in Nigeria. Renewable and sustainable energy reviews, 63, 172-192.

Brouwers, R., Schoubben, F., \& Van Hulle, C. (2018). The influence of carbon cost pass through on the link between carbon emission and corporate financial performance in the context of the European Union Emission Trading Scheme. Business Strategy and the Environment, 27(8), 1422-1436.

Brown, R. L., Durbin, J., \& Evans, J. M. (1975). Techniques for testing the constancy of regression relationships over time. Journal of the Royal Statistical Society: Series B (Methodological), 37(2), 149-163.

Carvalho, A., Xavier, G.C., Alexandre, J., Pedroti, L.G., Azevedo, A.R.G., Vieira, C.M.F., Monteiro, S.N. (2014) Environmental Durability of Soil-Cement Block Incorporated With Ornamental Stone Waste. Materials Science Forum. Vol. 798-799; pp. 548-553. Doi: https://doi.org/10.4028/www.scientific.net/MSF.798-799.548.

Charfeddine, L., \& Kahia, M. (2019). Impact of renewable energy consumption and financial development on $\mathrm{CO} 2$ emissions and economic growth in the MENA region: A panel vector autoregressive (PVAR) analysis. Renewable energy, 139, 198-213.

Chen, S., Saud, S., Bano, S., \& Haseeb, A. (2019). The nexus between financial development, globalization, and environmental degradation: Fresh evidence from Central and Eastern European Countries. Environmental Science and Pollution Research, 26(24), 24733-24747.

Danish \& Wang, Z. (2019). Investigation of the ecological footprint's driving factors: what we learn from the experience of emerging economies. Sustain Cities Soc 49:101626. https://doi.org/10.1016/j.scs.2019.101626

Danish \& Wang, Z. (2019). Investigation of the ecological footprint's driving factors: what we learn from the experience of emerging economies. Sustain Cities Soc 49:101626. https://doi.org/10.1016/j.scs.2019.101626 
Dar, J. A., \& Asif, M. (2017). Is financial development good for carbon mitigation in India? A regime shiftbased cointegration analysis. Carbon Management, 8(5-6), 435-443.

Destek, M. A. (2019). Financial Development and Environmental Degradation in Emerging Economies. In Energy and Environmental Strategies in the Era of Globalization (pp. 115-132). Springer, Cham.

Dietz, T., \& Rosa, E. A. (1994). Rethinking the environmental impacts of population, affluence and technology. Human ecology review, 1(2), 277-300.

Ehrlich, P. R., \& Holdren, J. P. (1971). Impact of population growth. Science, 171(3977), 1212-1217.

Gill A.R., Hassan S, \& Haseeb M (2019). Moderating role of financial development in environmental Kuznets: a case study of Malaysia. Environ SciPollut Res 26(33):34468-34478. https://doi.org/10. 1007/s11356-019-06565-1

Gokmenoglu, K. K., \& Sadeghieh, M. (2019). Financial development, CO2 emissions, fossil fuel consumption and economic growth: The case of Turkey. Strategic Planning for Energy and the Environment, 38(4), 7-28.

Gokmenoglu, K. K., Taspinar, N., \& Rahman, M. M. (2020). Military expenditure, financial development and environmental degradation in Turkey: A comparison of $\mathrm{CO} 2$ emissions and ecological footprint. International Journal of Finance \& Economics, 1-12.

Guo, M., \& Hu, Y. (2020). The Impact of Financial Development on Carbon Emission: Evidence from China. Sustainability, 12(17), 6959.

Gütschow, J. Jeffery, L. Gieseke, R. \&Günther, A. (2019). The PRIMAP-hist national historical emissions time series v2.1 (1850-2017). Potsdam: GFZ Data Services.

Gütschow, J., Jeffery, M. L., Gieseke, R., Gebel, R., Stevens, D., Krapp, M., \& Rocha, M. (2016). The PRIMAP-hist national historical emissions 5 time series, Earth System Science Data, 8, 571-603.

Gygli, S., Haelg, F., Potrafke, N., \& Sturm, J. E. (2019). The KOF globalisation index-revisited. The Review of International Organizations, 14(3), 543-574.

Hao, Y., Zhang, Z., Liao, H., Wei, Y. \& Wang, S. (2016), Is C02 emission a side effect of financial development? An empirical analysis for China. Environmental Science Pollution Res, 23(20), 21041-21057. 
Haseeb, A., Xia, E., Baloch, M. A., \& Abbas, K. (2018). Financial development, globalization, and CO 2 emission in the presence of EKC: evidence from BRICS countries. Environmental Science and Pollution Research, 25(31), 31283-31296.

Huang, L., \& Zhao, X. (2018). Impact of financial development on trade-embodied carbon dioxide emissions: Evidence from 30 provinces in China. Journal of Cleaner Production, 198, 721-736.

Ibrahim, M. H. (2018). Trade-finance complementarity and carbon emission intensity: panel evidence from middle-income countries. Environment Systems and Decisions, 38(4), 489-500.

IEA (2020). World Energy outlook 2020.

IPCC (2018) Global warming of $1.5^{\circ} \mathrm{C}$ : an IPCC special report on the impacts of global warming of $1.5^{\circ} \mathrm{C}$ above pre-industrial levels and related global greenhouse gas emission pathways, in the context of strengthening the global response to the threat of climate change. Retrieved from https://www.ipcc.ch/sr15/

Javid, M., \& Sharif, F. (2016). Environmental Kuznets curve and financial development in Pakistan. Renewable and Sustainable Energy Reviews, 54, 406-414.

Jiang, P., Yang, H., \& Ma, X. (2019). Coal production and consumption analysis, and forecasting of related carbon emission: evidence from China. Carbon Management, 10(2), 189-208.

Johnsson F, Kjärstad J. \&Rootzén, J. (2019) The threat to climate change mitigation posed by the abundance of fossil fuels. Clim Pol 19(2): 258-274

Jordan, S., \& Philips, A. Q. (2018). Cointegration testing and dynamic simulations of autoregressive distributed lag models. The Stata Journal, 18(4), 902-923.

Katircioğlu, S. T., \& Taşpinar, N. (2017). Testing the moderating role of financial development in an environmental Kuznets curve: empirical evidence from Turkey. Renewable and Sustainable Energy Reviews, 68, 572-586.

Kayani, G. M., Ashfaq, S., \& Siddique, A. (2020). Assessment of Financial Development on Environmental Effect: Implications for Sustainable Development. Journal of Cleaner Production, 120984.

Khan, M. I., Teng, J. Z., \& Khan, M. K. (2020). The impact of macroeconomic and financial development on carbon dioxide emissions in Pakistan: evidence with a novel dynamic simulated ARDL approach. Environmental Science and Pollution Research, 27(31), 39560-39571. 
Khan, N. H., Ju, Y., Latif, Z., \& Khan, K. (2020). Nexus between carbon emission, financial development, and access to electricity: Incorporating the role of natural resources and population growth. Journal of Public Affairs, e2131.

Khan, S., Peng, Z., \& Li, Y. (2019). Energy consumption, environmental degradation, economic growth and financial development in globe: Dynamic simultaneous equations panel analysis. Energy Reports, 5, 1089-1102.

Kim, D. H., Wu, Y. C., \& Lin, S. C. (2020). Carbon dioxide emissions and the finance curse. Energy Economics, 104788.

Kripfganz, S., \& Schneider, D. C. (2019). Response surface regressions for critical value bounds and approximate p-values in equilibrium correction models (No. 1901).

Kwakwa, P. A., Alhassan, H., \& Adu, G. (2018). Effect of natural resources extraction on energy consumption and carbon dioxide emission in Ghana. MPRA Paper No. 85401.

Lahiani, A. (2020). Is financial development good for the environment? An asymmetric analysis with CO 2 emissions in China. Environ SciPollut Res 27:7901-7909. https://doi.org/10.1007/s11356-01907467-y

Le Quéré, C., Andrew, R.M., Friedlingstein, P., Sitch, S., Pongratz, J., \& Zhu, D., (2018). Global Carbon Budget 2017. Earth Syst. Sci. Data 10, 405-448. https://doi.org/10.5194/essd-10-405- 2018

Lee, J., \& Strazicich, M. C. (2003). Minimum Lagrange multiplier unit root test with two structural breaks. Review of economics and statistics, 85(4), 1082-1089.

Letcher, T. M. (2020). Introduction with a Focus on Atmospheric Carbon Dioxide and Climate Change. In Future energy (pp. 3-17). Elsevier.

Letcher, T. M. (Ed.). (2020). Future energy: improved, sustainable and clean options for our planet. Elsevier.

Lin, B., \& Agyeman, S. D. (2020). Assessing Sub-Saharan Africa's low carbon development through the dynamics of energy-related carbon dioxide emissions. Journal of Cleaner Production, 274, 122676.

Liu, H., \& Song, Y. (2020). Financial development and carbon emissions in China since the recent world financial crisis: Evidence from a spatial-temporal analysis and a spatial Durbin model. Science of The Total Environment, 715, 136771. 
Lu, W. C. (2018). The impacts of information and communication technology, energy consumption, financial development, and economic growth on carbon dioxide emissions in 12 Asian countries. Mitigation and Adaptation Strategies for Global Change, 23(8), 1351-1365.

Mendes, B.C., Pedroti, L.G., Fontes, M.P.F., Ribeiro, J.C.L., Vieira, C.M.F., Pacheco, A.A., \& Azevedo, A.R.G. (2019) Technical and environmental assessment of the incorporation of iron ore tailings in construction clay bricks. Construction and Building Materials. 227(2019) 116669. https://doi.org/10.1016/j.conbuildmat.2019.08.050.

Nag, B., \& Parikh, J. (2000) Indicators of carbon emission intensity from commercial energy use in India. Energy Economics. 22(2000); 441-461.

Narayan, P. K., \& Narayan, S. (2010). Carbon dioxide emissions and economic growth: Panel data evidence from developing countries. Energy policy, 38(1), 661-666.

Nwani, C., \& Omoke, P. C. (2020). Does bank credit to the private sector promote low-carbon development in Brazil? An extended STIRPAT analysis using dynamic ARDL simulations. Environmental Science and Pollution Research International. 27, 31408-31426

Omoke, P. C., Nwani, C., Effiong, E. L., Evbuomwan, O. O., \& Emenekwe, C. C. (2020). The impact of financial development on carbon, non-carbon, and total ecological footprint in Nigeria: new evidence from asymmetric dynamic analysis. Environmental Science and Pollution Research, 119.

Paramati, S. R., Mo, D., \& Huang, R. (2020). The role of financial deepening and green technology on carbon emissions: Evidence from major OECD economies. Finance Research Letters, 101794.

Pesaran, M. H., Shin, Y., \& Smith, R. J. (2001). Bounds testing approaches to the analysis of level relationships. Journal of applied econometrics, 16(3), 289-326.

Rafindadi, A.A. (2016). Does the need for economic growth influence energy consumption and CO2 emissions in Nigeria? Evidence from the innovation accounting test. Renew SustEnerg Rev 62:1209-1225

Riti, J.S., \& Shu, Y. (2016). Renewable energy, energy efficiency, and eco friendly environment (RE 5) in Nigeria. Energy Sustain Soc 6(1):13

Salahuddin, M., Alam, K., Ozturk, I., \& Sohag, K. (2018). The effects of electricity consumption, economic growth, financial development and foreign direct investment on $\mathrm{CO} 2$ emissions in Kuwait. Renewable and Sustainable Energy Reviews, 81, 2002-2010. 
Salahuddin, M., Gow, J., \& Ozturk, I. (2015). Is the long-run relationship between economic growth, electricity consumption, carbon dioxide emissions and financial development in Gulf Cooperation Council Countries robust?. Renewable and Sustainable Energy Reviews, 51, 317-326.

Sarkodie, S. A., \& Owusu, P. A. (2020). How to apply the novel dynamic ARDL simulations (dynardl) and Kernel-based regularized least squares (krls). MethodsX, 7, 101160.

Saud, S., Chen, S., \& Haseeb, A. (2020). The role of financial development and globalization in the environment: Accounting ecological footprint indicators for selected one-belt-one-road initiative countries. Journal of Cleaner Production, 250, 119518.

Sethi, P., Chakrabarti, D., \& Bhattacharjee, S. (2020). Globalization, financial development and economic growth: perils on the environmental sustainability of an emerging economy. Journal of Policy Modeling, 42,(3), 520-535.

Shahbaz M, Shahzad SJH, Ahmad N and Alam S (2016). Financial development and environmental quality: the way forward. Energy Policy 98: 353-364

Shahbaz, M., Nasir, M. A., Hille, E., \& Mahalik, M. K. (2020). UK's net-zero carbon emissions target: Investigating the potential role of economic growth, financial development, and R\&D expenditures based on historical data (1870-2017).Technological Forecasting and Social Change, 161, 120255.

Shahbaz, M., Zakaria, M., Shahzad, S. J. H., \& Mahalik, M. K. (2018). The energy consumption and economic growth nexus in top ten energy-consuming countries: Fresh evidence from using the quantile-on-quantile approach. Energy Economics, 71, 282-301.

Shen, Y., Su, Z. W., Yousaf, M., Umar, M., Khan, Z., \& Khan, M. (2020). Does Green Investment, Financial Development and Natural Resources Rent Limit Carbon Emissions? A Provincial Panel Analysis of China. Science of The Total Environment, 142538.

Shoaib, H. M., Rafique, M. Z., Nadeem, A. M., \& Huang, S. (2020). Impact of financial development on CO 2 emissions: A comparative analysis of developing countries (D 8) and developed countries (G 8). Environmental Science and Pollution Research, 1-15.

Tahir, T., Luni, T., Majeed, M. T., \& Zafar, A. (2020). The impact of financial development and globalization on environmental quality: evidence from South Asian economies. Environmental Science and Pollution Research, 1-14.

Tian, Y., Chen, W., \& Zhu, S. (2017). Does financial macroenvironment impact on carbon intensity: evidence from ARDL-ECM model in China. Natural Hazards, 88(2), 759-777. 
Trinks, A., Mulder, M., \& Scholtens, B. (2020). An efficiency perspective on carbon emissions and financial performance. Ecological Economics, 175, 106632.

Vujovic, T., Petkovic, Z., Pavlovic, M., \& Jovic, S. (2018) Economic growth based in carbon dixiode emission intensity. Physica, A (Statistical Mechanics and its Applications). DOI: https://doi.org/10.1016/j.physa.2018.04.074

Wang, J., \& Dong, K. (2019). What drives environmental degradation? Evidence from 14 sub-Saharan African countries. Sci Total Environ 656:165-173

Wang, L., Vo, X. V., Shahbaz, M., \& Ak, A. (2020). Globalization and carbon emissions: Is there any role of agriculture value-added, financial development, and natural resource rent in the aftermath of COP21?. Journal of Environmental Management, 268, 110712.

WDI (2020) World development indicators, World Bank. Available online: https://databank.worldbank.org/home.aspx

WWF (2018). Living Planet Report - 2018: Aiming Higher. In: Grooten M, Almond REA (eds). WWF, Gland

Xie, N., Hu, H., Fang, D., Shi, X., Luo, S., \& Burns, K. (2020). An empirical analysis of financial markets and instruments influencing the low-carbon electricity production transition. Journal of Cleaner Production, 124415.

Xing, T., Jiang, Q., Ma, X. (2017), To facilitate or curb? The role of financial development in China's carbon emissions reduction process: A novel approach. International Journal of Environmental Research and Public Health, 14(10), 1-39.

Yao, X. \& Tang, X. (2020) Does financial structure affect C02 emissions: Evidence from G-20 countries. Finance Research Letters. DOI: https://doi.org/10.1016/j.frl.2020.101791

Yasin, I., Ahmad, N., \& Chaudhary, M. A. (2020). Catechizing the Environmental-Impression of Urbanization, Financial Development, and Political Institutions: A Circumstance of Ecological Footprints in 110 Developed and Less-Developed Countries. Social Indicators Research, 147(2), 621-649.

York, R., Rosa, E. A., \& Dietz, T. (2003). STIRPAT, IPAT and ImPACT: analytic tools for unpacking the driving forces of environmental impacts. Ecological economics, 46(3), 351-365. 
Zafar, M. W., Zaidi, S. A. H., Sinha, A., Gedikli, A., \& Hou, F. (2019). The role of stock market and banking sector development, and renewable energy consumption in carbon emissions: insights from G-7 and N-11 countries. Resources Policy, 62, 427-436.

Zaidi, S. A. H., Zafar, M. W., Shahbaz, M., \& Hou, F. (2019). Dynamic linkages between globalization, financial development and carbon emissions: Evidence from Asia Pacific Economic Cooperation countries. Journal of Cleaner Production, 228, 533-543.

Zhang, S., \& Zhao, T. (2019). Identifying major influencing factors of CO2 emissions in China: regional disparities analysis based on STIRPAT model from 1996 to 2015. Atmospheric Environment, 207, 136-147.

Zhao, B., \& Yang, W. (2020). Does financial development influence CO2 emissions? A Chinese provincelevel study. Energy, 117523.

Zhao, S., Fan, J. \& Sun, W. (2014) Utilisation of iron-ore tailings as fine aggregate in ultra-high performance concrete. Construction and Building Materials. Vol. 50; 540-548. 
1181

1182

1183

1184

1185

1186

1187

1188

1189

1190

1191

1192

1193

1194

1195

1196

1197

1198

1199

1200

1201

1202

1203

1204

1205

1206

1207

1208 
1210 


\section{Figures}

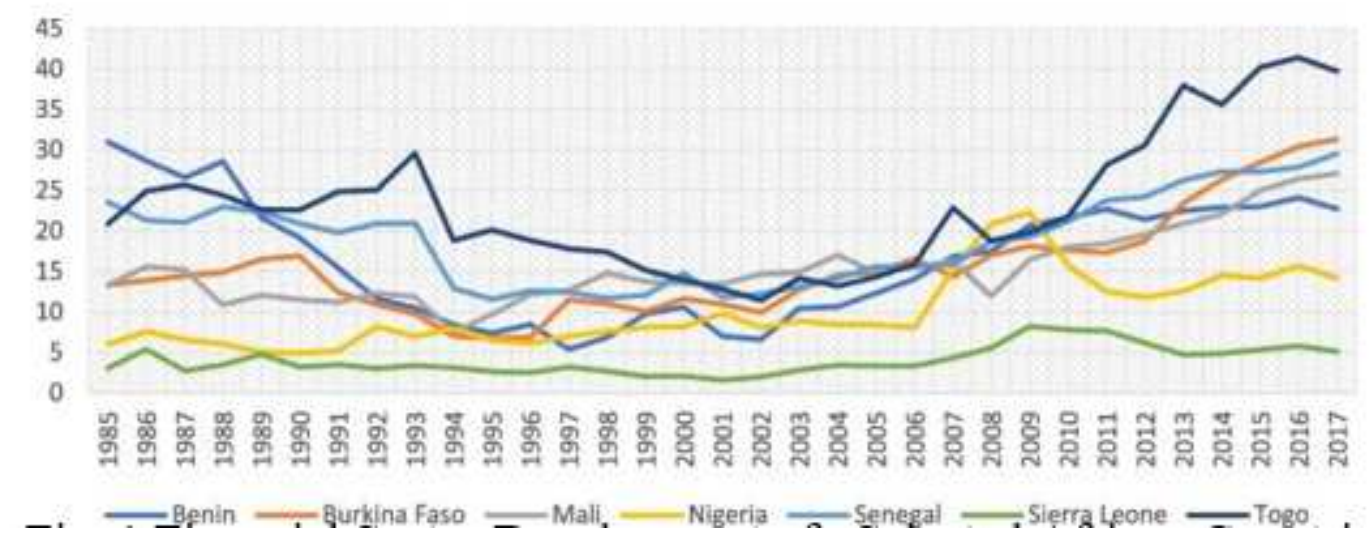

\section{Figure 1}

Financial Sector Development of Selected African Countries Source: WDI (2019)

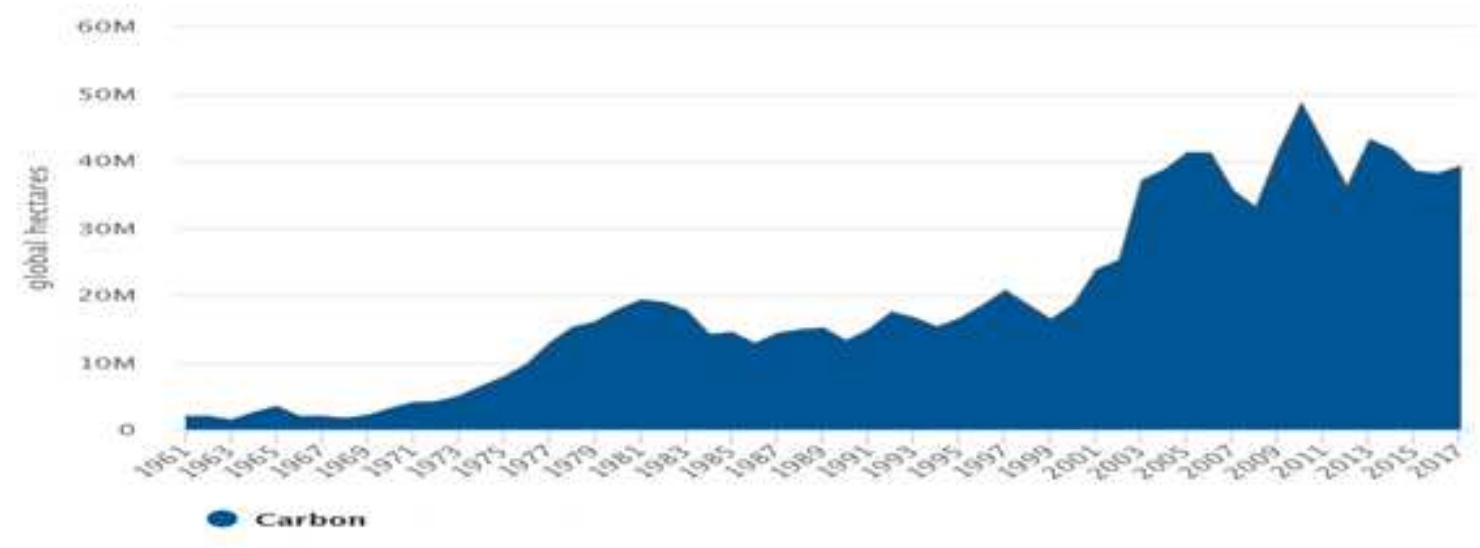

Figure 2

Global Footprint Network 2021 Data source: Global Footprint Network 2021 


\section{- Dynamic ARDL Simulations}

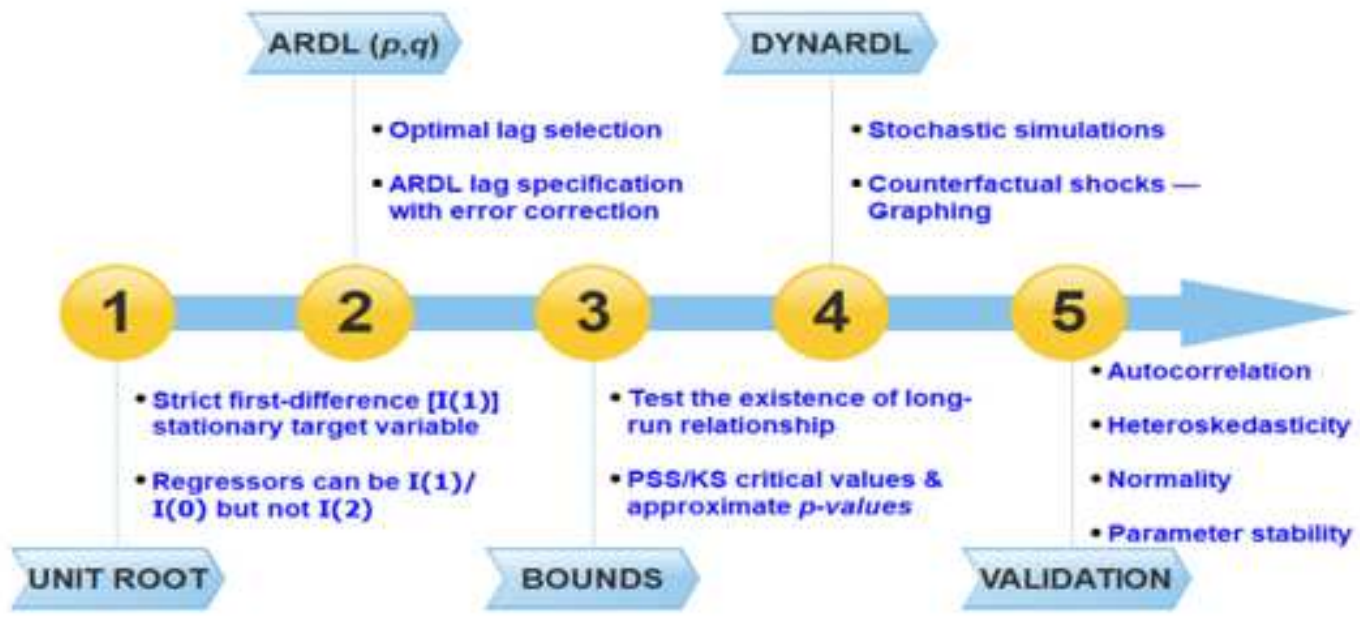

Figure 3

Econometric steps in the application of Dynamic ARDL Simulation Sources: Sarkodie and Owusu (2020) 

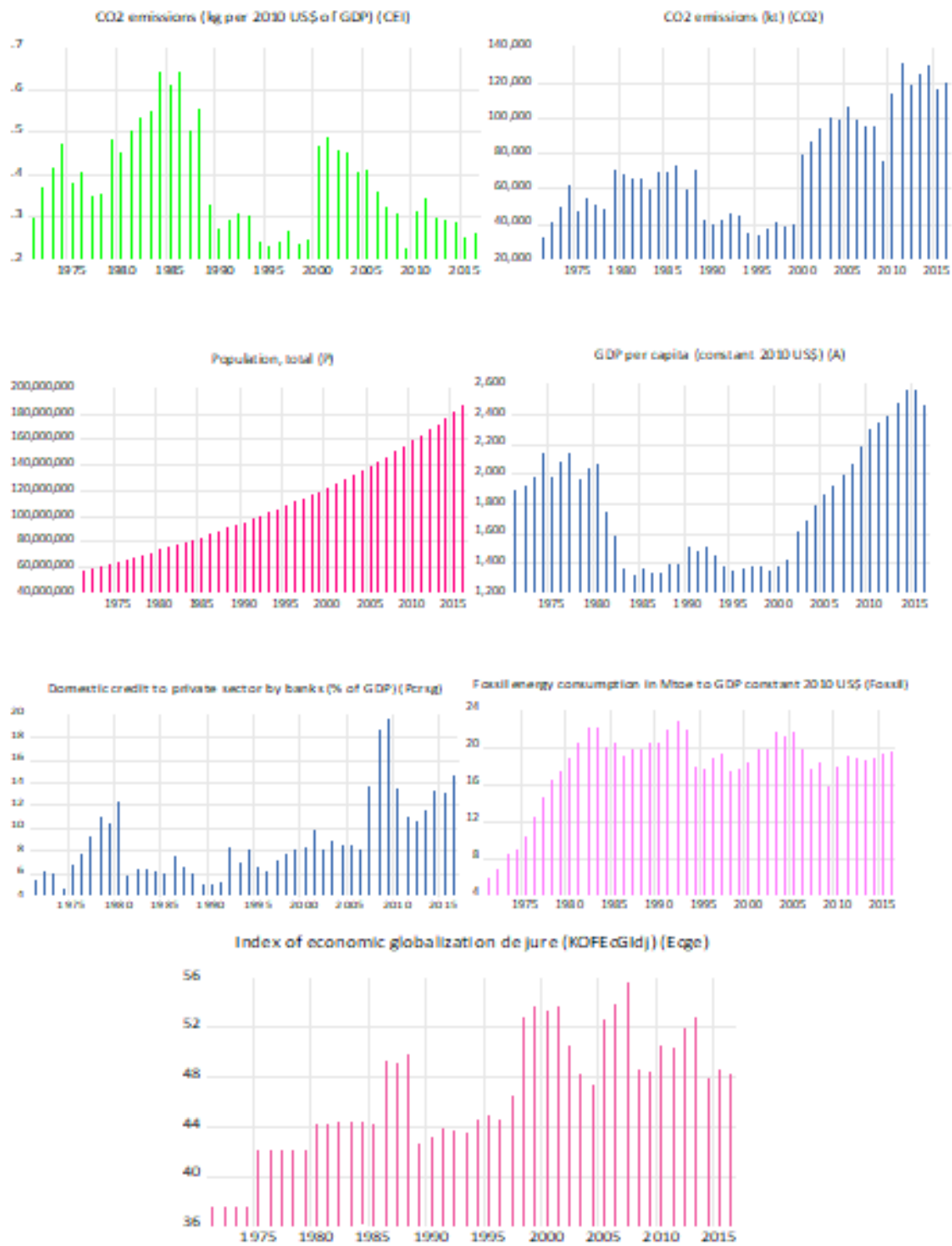

\section{Figure 4}

Line plot of the variables from 1971 to 2016 . Sources see in Table 2 above 

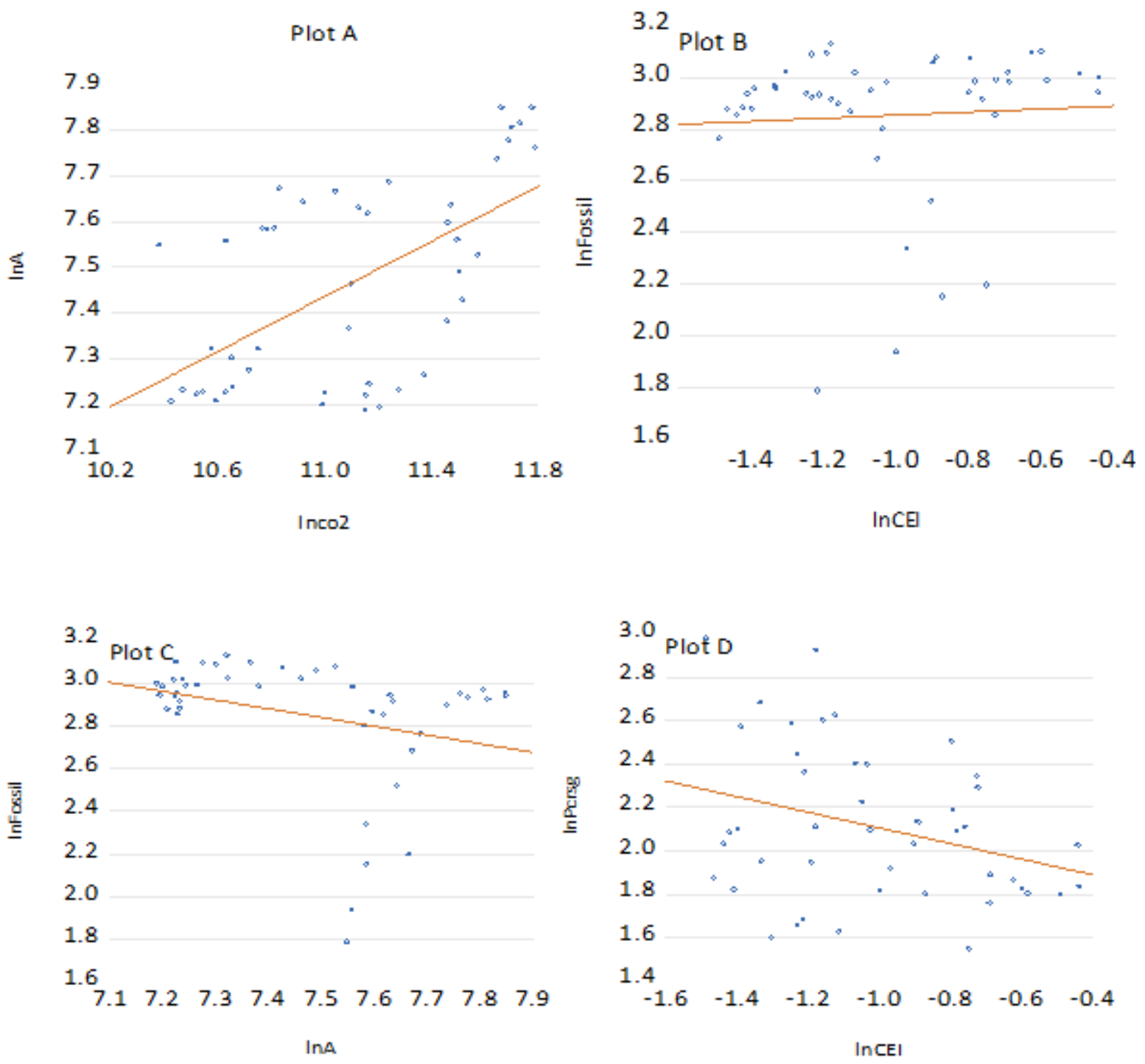

Figure 5

Scatter plots showing the partial correlations of the variables the study

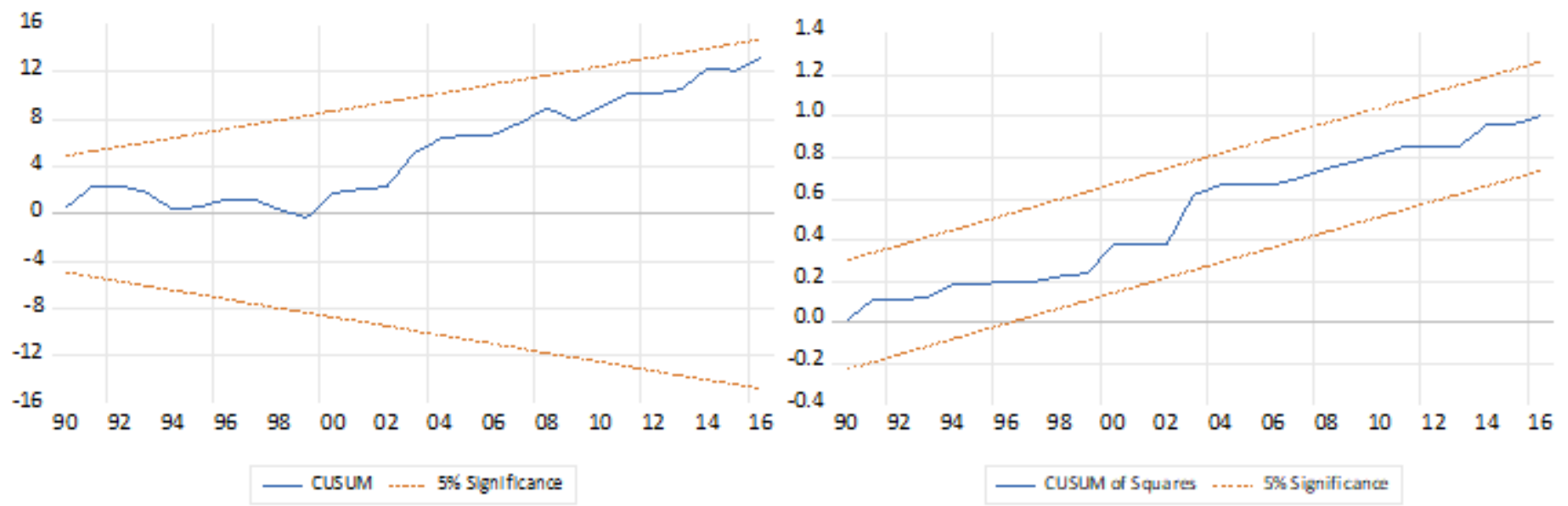

Figure 6 
Equation 7 - CUSUM and CUSUMSQ for CO2
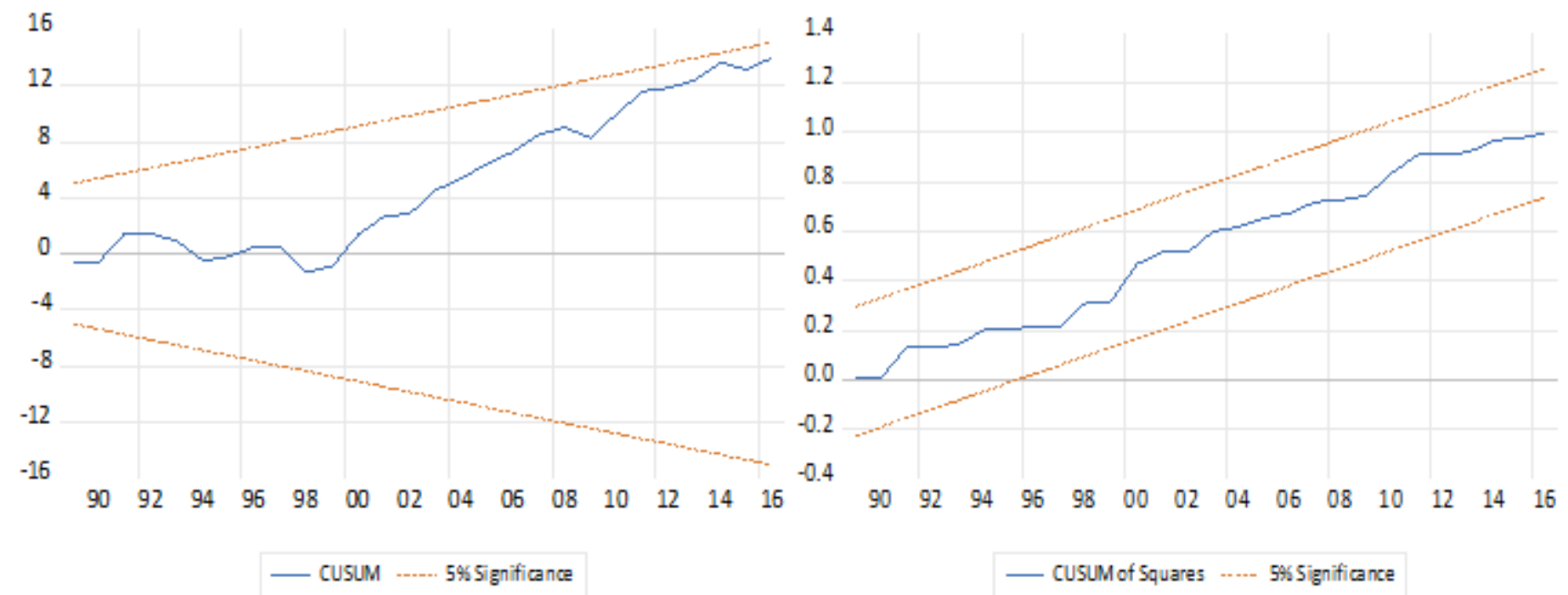

Figure 7

Equation 8- CUSUM and CUSUMSQ for CO2
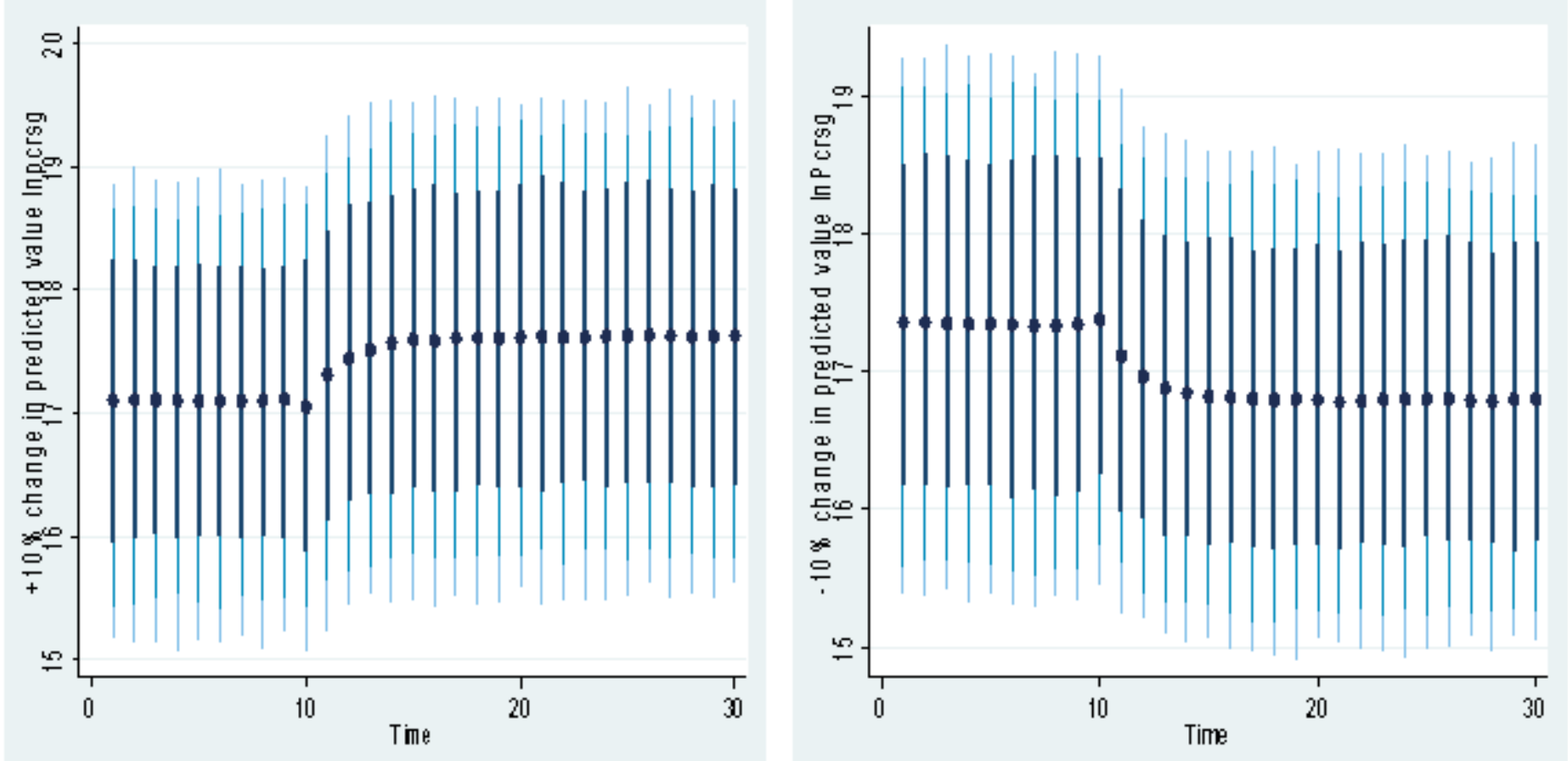

Figure 8

positive or negative $10 \%$ innovation in predicted InPcrsg on InCO2. The dots and dark blue to light blue lines explain average predicted value and $75 \%, 90 \%$, and $95 \%$ confidence intervals respectively 

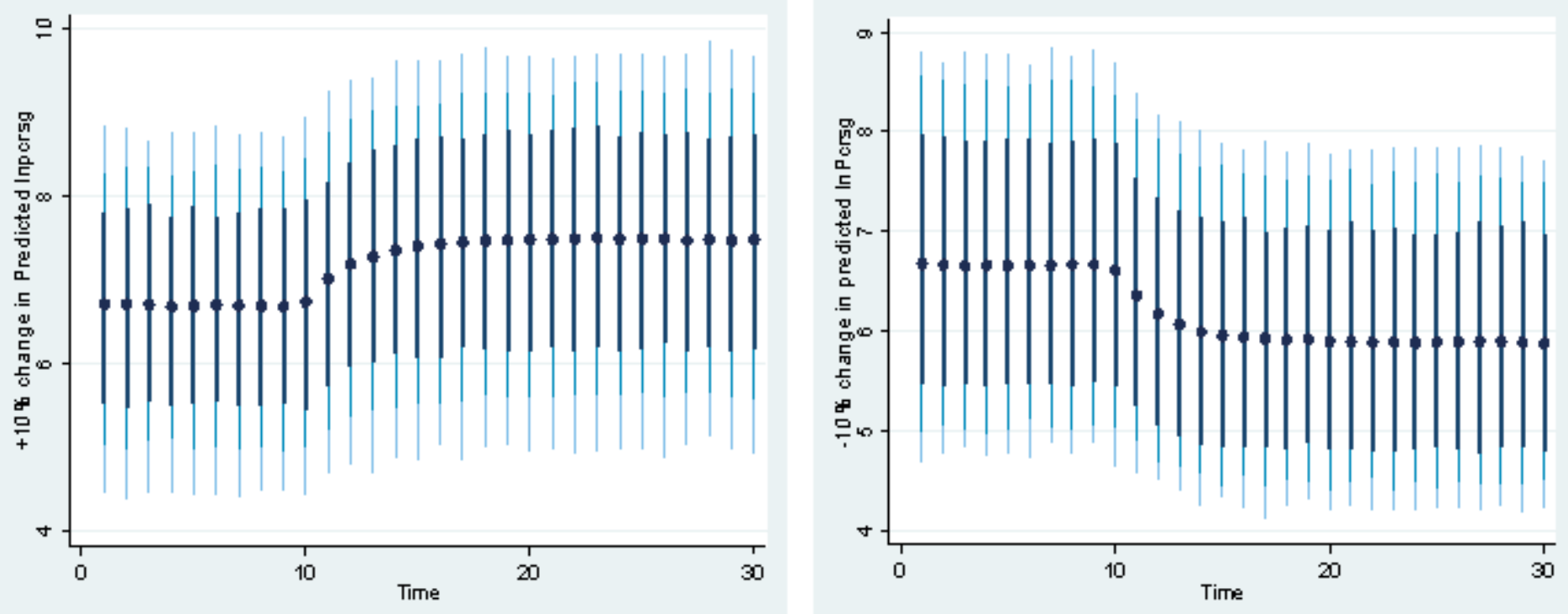

\section{Figure 9}

positive or negative $10 \%$ innovation in predicted InPcrsg on InCEl. The dots and dark blue to light blue lines explain average predicted value and $75 \%, 90 \%$, and $95 \%$ confidence intervals respectively
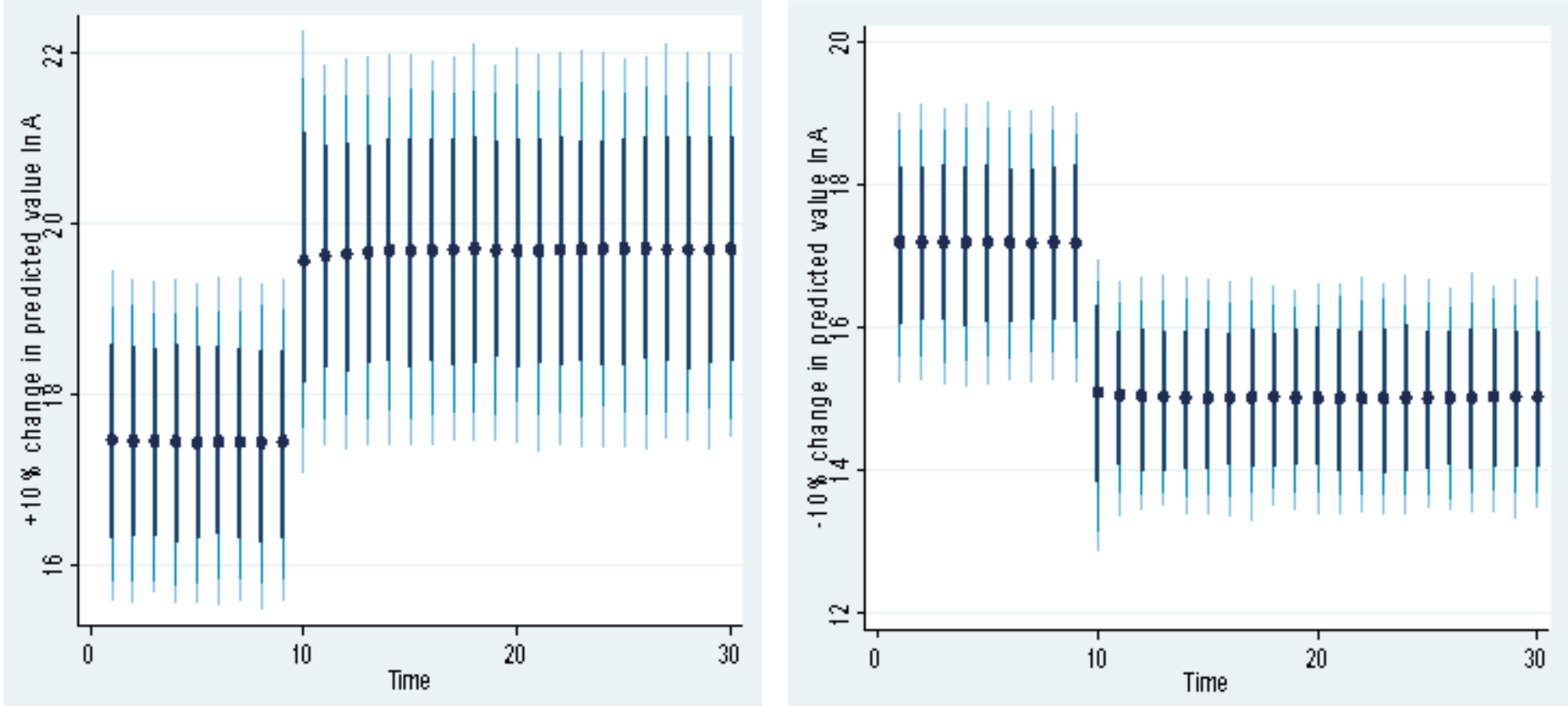

Figure 10

positive or negative $10 \%$ innovation in predicted $\ln A$ on $\ln C 02$. The dots and dark blue to light blue lines explain average predicted value and $75 \%, 90 \%$, and $95 \%$ confidence intervals respectively 

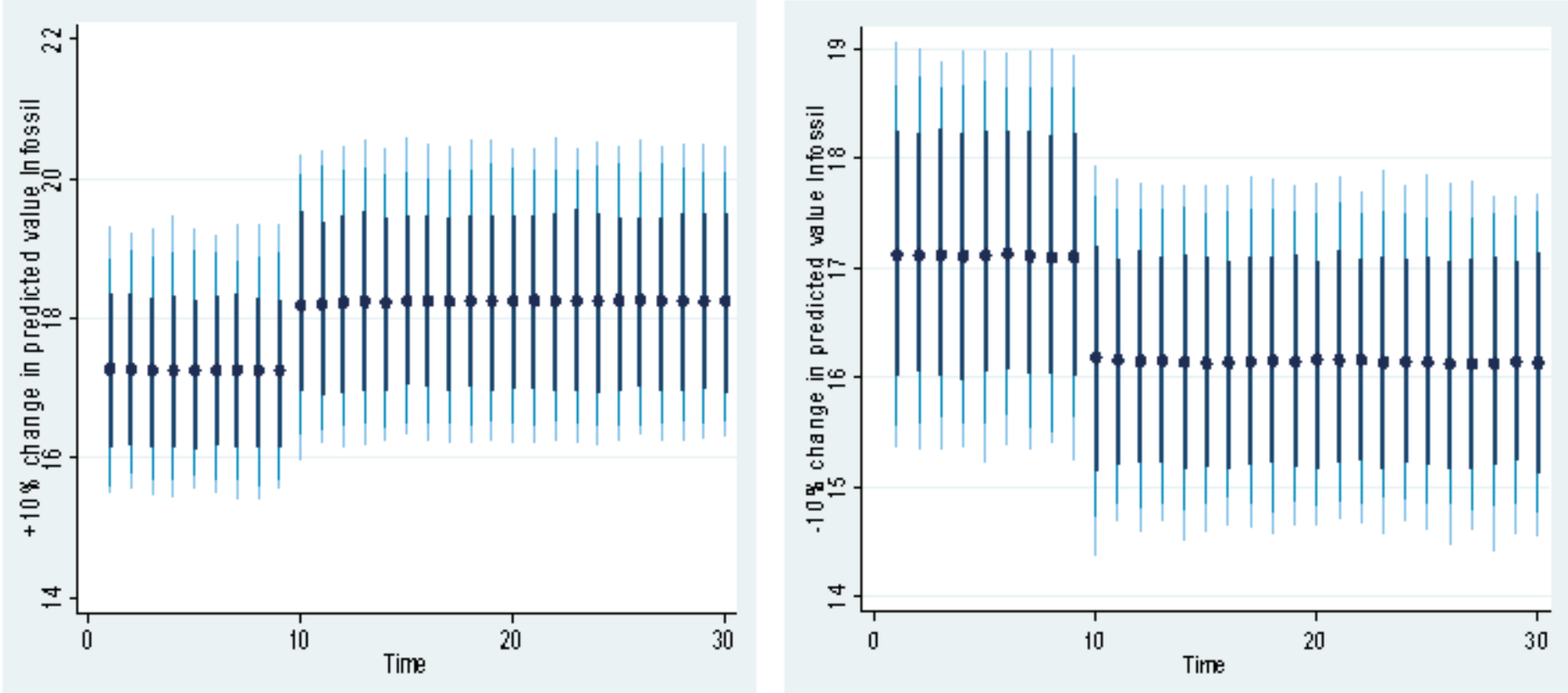

Figure 11

positive or negative $10 \%$ innovation in predicted InFossil on InCO2. The dots and dark blue to light blue lines explain average predicted value and $75 \%, 90 \%$, and $95 \%$ confidence intervals respectively
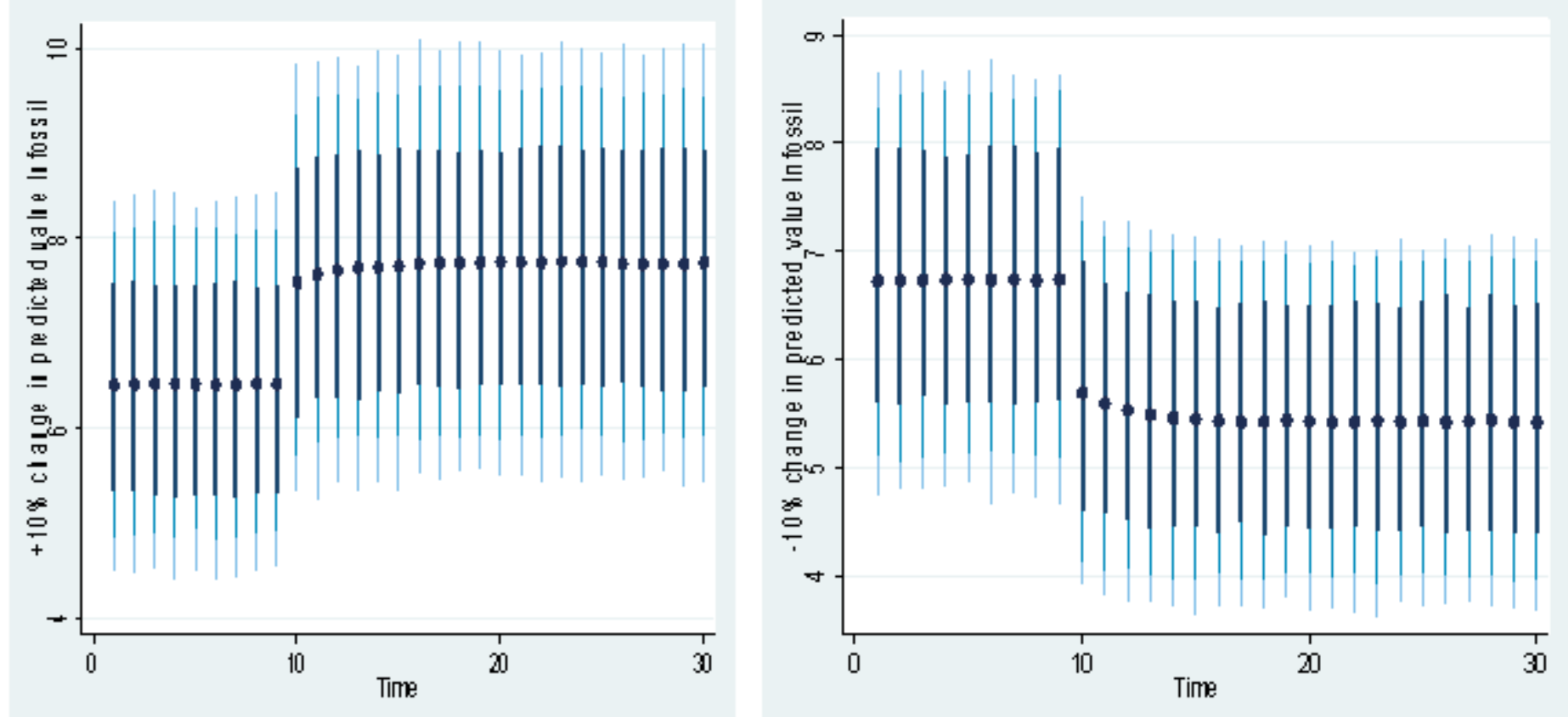

Figure 12

positive or negative $10 \%$ innovation in predicted InFossil on InCEI. The dots and dark blue to light blue lines explain average predicted value and $75 \%, 90 \%$, and $95 \%$ confidence intervals respectively 

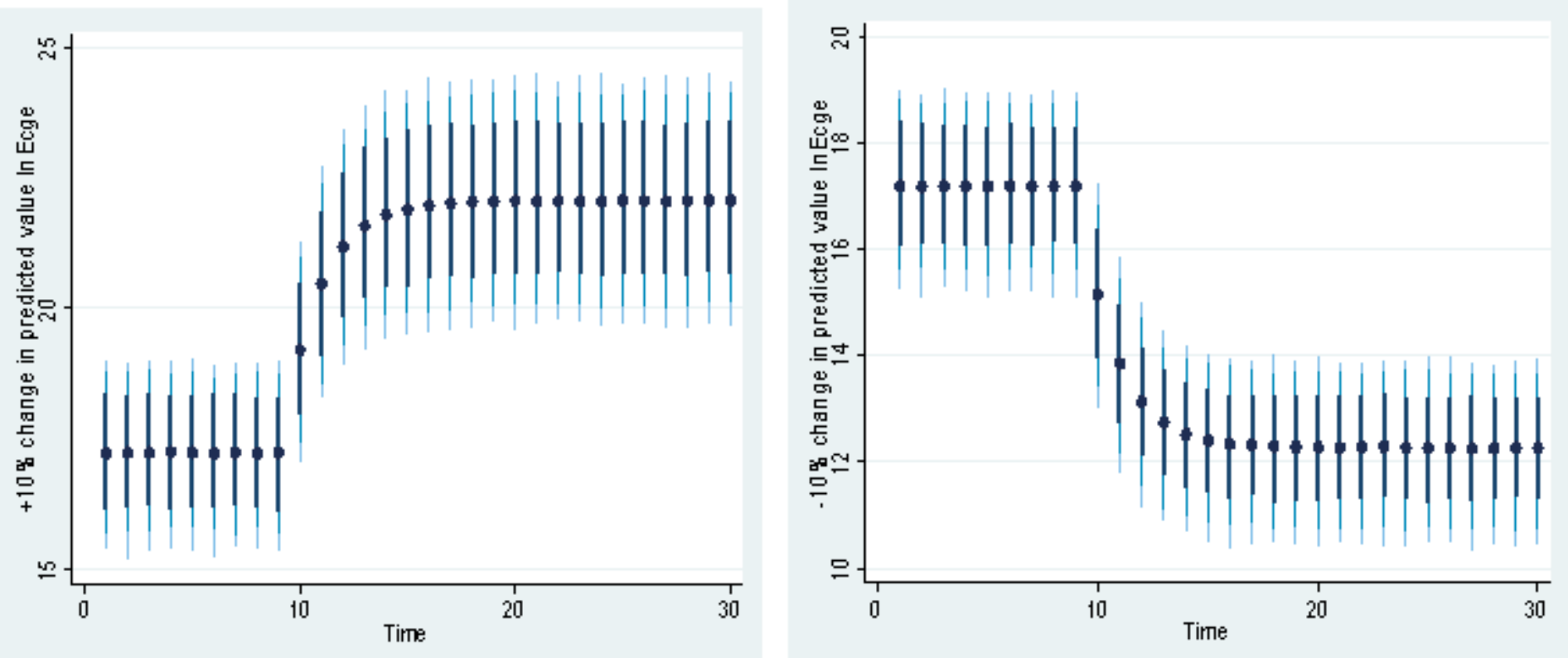

Figure 13

positive or negative 10\% innovation in predicted InEcge on InCO2. The dots and dark blue to light blue lines explain average predicted value and $75 \%, 90 \%$, and $95 \%$ confidence intervals respectively
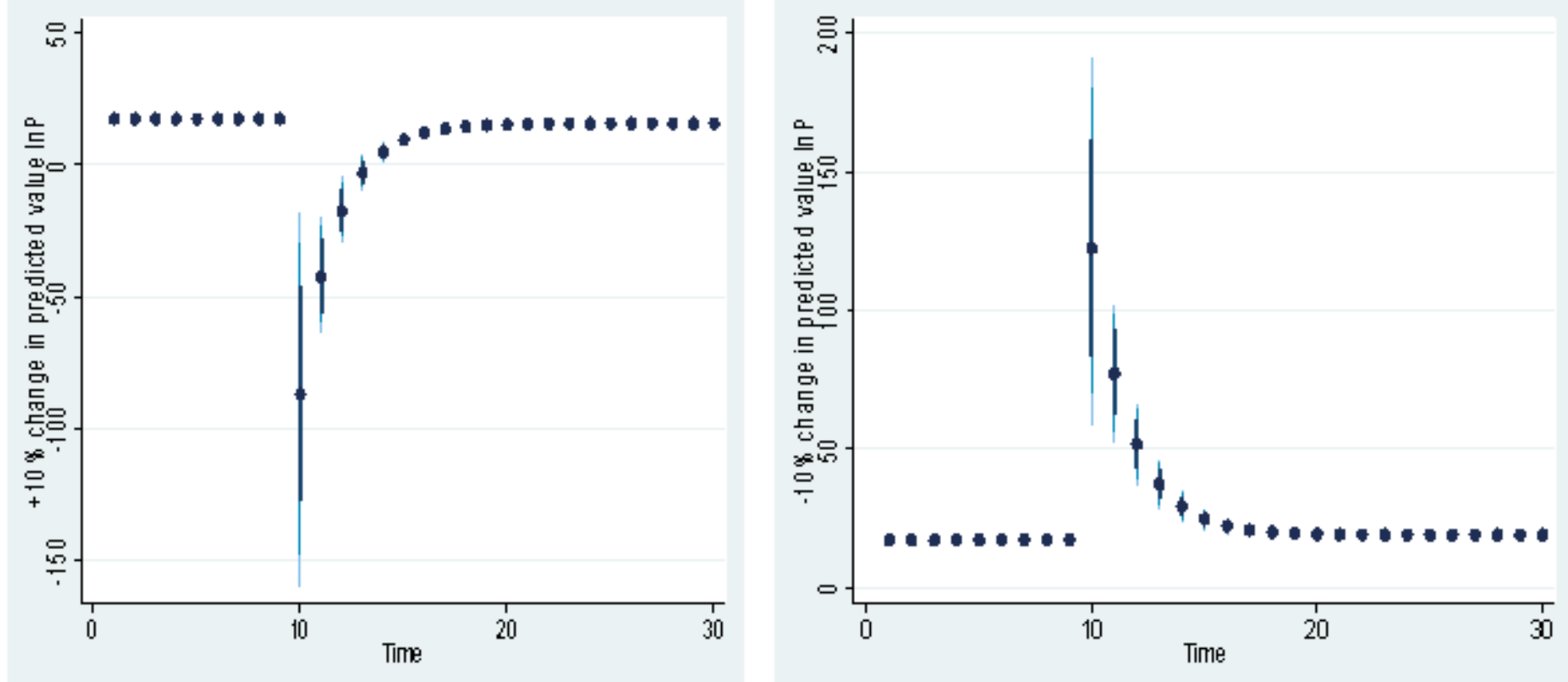

Figure 14

positive or negative $10 \%$ innovation in predicted $(\mathrm{InP})$ on $\operatorname{lnCO} 2$. The dots and dark blue to light blue lines explain average predicted value and $75 \%, 90 \%$, and $95 \%$ confidence intervals respectively 